Supporting Information

\title{
Optimized Molecular Packing and Non-radiative Energy Loss Based on Terpolymer Methodology Combining Two Asymmetric Segments for High-Performance Polymer Solar Cells
}

Xunchang Wang, ${ }^{\dagger}, \perp$ Jianhua Han, ${ }^{\dagger}$ Da Huang,,${ }^{\ddagger}$ Jianing Wang, ${ }^{\S}$ Yuan Xie,,${ }^{\natural}$ Zhilin Liu, ${ }^{\dagger}$ Yonghai Li, ${ }^{\dagger}$ Chunming Yang, ${ }^{*, \neq}$ Yong Zhang, ${ }^{\S}$ Zhicai He, ${ }^{\dagger}$ Xichang Bao*,† and Renqiang Yang ${ }^{*, \dagger}$

$\dagger$ CAS Key Laboratory of Bio-based Materials, Qingdao Institute of Bioenergy and Bioprocess Technology, Chinese Academy of Sciences, Qingdao 266101, China

¥ Shanghai Synchrotron Radiation Facility, Shanghai Institute of Applied Physics, Chinese Academy of Sciences, Shanghai 201204, China

$\S$ Guangdong Provincial Key Laboratory of Nanophotonic Functional Materials and Devices, Institute of Semiconductor Science and Technology, South China Normal University, Guangzhou 510631, China

" Institute of Polymer Optoelectronic Materials and Devices, State Key Laboratory of Luminescent Materials and Devices, South China University of Technology, Guangzhou 510640, China ${ }^{\perp}$ Center of Materials Science and Optoelectronics Engineering, University of Chinese Academy of Sciences, Beijing 100049, China

*C. Yang. Email: yangchunming@zjlab.org.cn

*X. Bao. Email: baoxc@qibebt.ac.cn

*R. Yang. Email: yangrq@qibebt.ac.cn 


\section{Experimental Section}

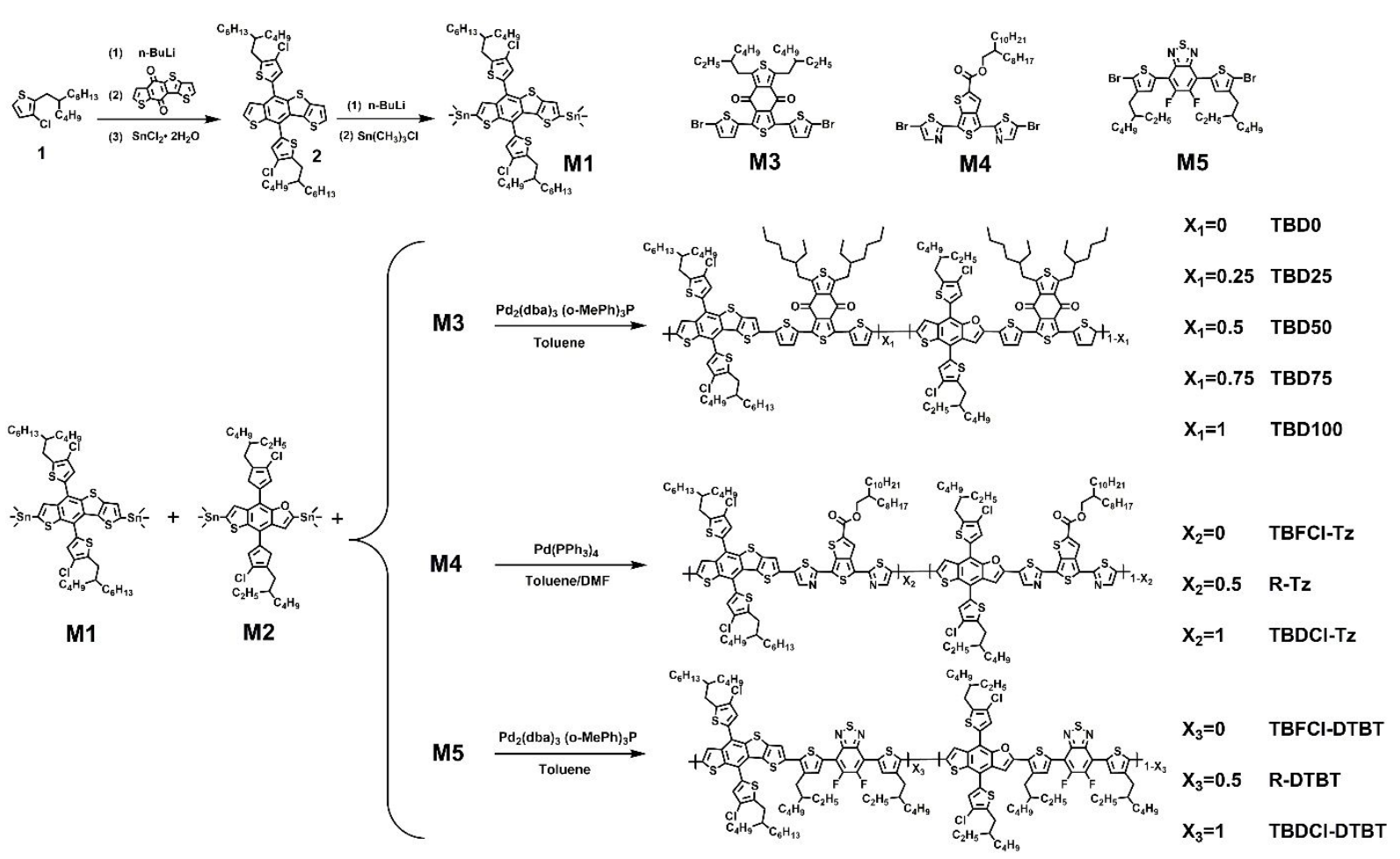

Scheme S1. The synthetic routes of the monomers and polymers.

\section{Materials}

All the reagents, unless otherwise specified, were purchased from Sigma-Aldrich Co., J\&K, and Tokyo Chemical Industry Co., Ltd., and were used without further purification. IT-4F was purchased from Solarmer Materials Inc. Compound 1, thienobenzodithiophene-4,12dione, M2, M3, M4 and M5 were synthesized by the reported method and characterized by NMR before use. ${ }^{[1-4]}$ The general synthetic routes for monomers and polymers are shown in Scheme S1. The detailed synthetic procedures are as follows.

Synthesis of Compound 2: To a solution of compound 1 (6.19 g, $21.60 \mathrm{mmol})$ in THF (90 $\mathrm{mL})$ was slowly added $\mathrm{n}$-BuLi in hexane $(11.7 \mathrm{~mL}, 18.72 \mathrm{mmol}, 1.6 \mathrm{M})$ at $-78^{\circ} \mathrm{C}$ under the protection of $\mathrm{Ar}$ atmosphere, and the reaction mixture was stirred at $-78{ }^{\circ} \mathrm{C}$ for $3 \mathrm{~h}$. Then the suspension of thienobenzodithiophene-4,12-dione ( $7.19 \mathrm{mmol}, 2 \mathrm{~g})$ dispersed in $20 \mathrm{~mL}$ THF was added slowly and stirred for another $3 \mathrm{~h}$ at $-78^{\circ} \mathrm{C}$, followed by slowly warming up to room temperature and stired over night. Subsequently, Tin (II) chloride dihydrate (13.00 g, $57.57 \mathrm{mmol})$ dissolved in $10 \%$ aqueous $\mathrm{HCl}(20 \mathrm{~mL})$ was added and then the resulting 
solution was stirred for an additional $3 \mathrm{~h}$ at $50{ }^{\circ} \mathrm{C}$. Cooled the reaction to room temperature, the reaction was poured into water and extracted three times with dichloromethane. The combined organic layer was washed with water, and then dried over anhydrous sodium sulfate. After removal of the solvent, the crude product was purified by column chromatography over silica gel (eluent: petroleum ether) to afford compound 2 as light yellow oil (3.34 g, yield: 56.9 \%). ${ }^{1} \mathrm{H}$ NMR $\left(\mathrm{CDCl}_{3}, 600 \mathrm{MHz}\right), \delta(\mathrm{ppm}): 7.59$ (d, 1H), $7.50(\mathrm{~d}, 1 \mathrm{H}), 7.43(\mathrm{~d}, 1 \mathrm{H}), 7.26$ $(\mathrm{d}, 1 \mathrm{H}), 7.24(\mathrm{~s}, 1 \mathrm{H}), 7.11(\mathrm{~s}, 1 \mathrm{H}), 2.90(\mathrm{~m}, 2 \mathrm{H}), 2.85(\mathrm{~m}, 2 \mathrm{H}), 1.80(\mathrm{~m}, 2 \mathrm{H}), 1.37-1.26(\mathrm{~m}$, $32 \mathrm{H}), 0.95-0.84(\mathrm{~m}, 12 \mathrm{H})$.

Synthesis of Compound M1: To a solution of compound 2 (1.25 g, $1.53 \mathrm{mmol})$ in THF (30 $\mathrm{mL})$ was added $\mathrm{n}$-BuLi in hexane $(5.36 \mathrm{~mL}, 3.35 \mathrm{mmol}, 1.6 \mathrm{M})$ slowly at $-78^{\circ} \mathrm{C}$ under argon protection, and the mixture was stirred at $-78^{\circ} \mathrm{C}$ for $3 \mathrm{~h}$. Then trimethyltin chloride in THF $(6.12 \mathrm{~mL}, 6.12 \mathrm{mmol}, 1 \mathrm{M})$ was added in one portion and again stirred for $1 \mathrm{~h}$ at $-78{ }^{\circ} \mathrm{C}$, then slowly warmed up to room temperature for $5 \mathrm{~h}$. The solution was poured into cold deionized water and extracted with diethyl ether three times. The combined organic layer was washed with deionized water three times and dried over anhydrous sodium sulfate. After removal of the solvent, the crude product was washed with ethanol twice to afford desirable product $\mathbf{M 1}$ as light yellow waxy liquid $(0.42 \mathrm{~g}, 24.0 \%$ yield $) .{ }^{1} \mathrm{H}$ NMR $\left(\mathrm{CDCl}_{3}, 600 \mathrm{MHz}\right), \delta(\mathrm{ppm})$ : 7.59(s, 1H), $7.27(\mathrm{~s}, 1 \mathrm{H}), 7.23(\mathrm{~s}, 1 \mathrm{H}), 7.12(\mathrm{~s}, 1 \mathrm{H}), 2.91(\mathrm{~m}, 2 \mathrm{H}), 2.86(\mathrm{~m}, 2 \mathrm{H}), 1.85(\mathrm{~m}, 2 \mathrm{H})$,

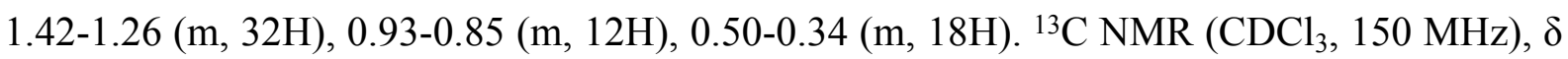
(ppm): 145.04, 144.51, 143.06, 141.99, 141.02, 138.97, 138.85, 138.39, 137.43, 135.54, $134.62,130.48,129.38,128.39,128.03,126.93,123.85,122.74,122.63,120.82,39.40,33.52$, $33.0332 .52,31.95,29.70,28.93,28.91,26.98,26.61,23.11,22.71,14.16,13.72,10.80,-8.11$, $-8.30,-10.34$

Synthesis of polymer TBD0: In a dry flask, $\mathrm{Pd}_{2}(\mathrm{dba})_{3} \quad\left(\begin{array}{lll}2 & \mathrm{mg})\end{array}\right.$ and tris(3methoxyphenyl)phosphine (4 mg) were added to a solution of $\mathbf{M 2}(95.7 \mathrm{mg}, 0.1 \mathrm{mmol})$ and M3 (76.7 $\mathrm{mg}, 0.1 \mathrm{mmol})$ in anhydrous toluene $(8 \mathrm{~mL})$ under nitrogen atmosphere and stirred 
at $110^{\circ} \mathrm{C}$ for $16 \mathrm{~h}$. The reaction mixture was cooled to room temperature and precipitated by addition of methanol $(50 \mathrm{~mL})$. The precipitates were collected by filtration and then extracted with ethanol, hexane, dichloromethane and toluene in a Soxhlet extractor to remove oligomers and residual catalyst. The toluene solution was concentrated and added to the methanol (30 $\mathrm{mL}$ ) to give TBD0 as a dark solid (86 mg, 69.5\% yield). GPC: $M_{\mathrm{n}} / \mathrm{PDI}=60.4 \mathrm{kDa} / 2.10$. $\mathrm{Td}=420{ }^{\circ} \mathrm{C}$. Anal. calcd for $\mathrm{C}_{68} \mathrm{H}_{76} \mathrm{Cl}_{2} \mathrm{O}_{3} \mathrm{~S}_{7}$ : C 65.94, H 6.35, S 18.12; found: $\mathrm{C} 67.02, \mathrm{H}$ 7.05, S 17.38.

Synthesis of polymer TBD25: In a dry flask, $\mathrm{Pd}_{2}(\mathrm{dba})_{3} \quad(2 \mathrm{mg})$ and tris(3methoxyphenyl)phosphine (4 mg) were added to a solution of M1 (28.6 mg, $0.025 \mathrm{mmol})$, M2 $(71.8 \mathrm{mg}, 0.075 \mathrm{mmol})$ and $\mathbf{M 3}(76.7 \mathrm{mg}, 0.1 \mathrm{~mol})$ in anhydrous toluene $(8 \mathrm{~mL})$ under nitrogen atmosphere and stirred at $110{ }^{\circ} \mathrm{C}$ for $16 \mathrm{~h}$. The reaction mixture was cooled to room temperature and precipitated by addition of methanol $(50 \mathrm{~mL})$. The precipitates were collected by filtration and then extracted with ethanol, hexane, dichloromethane and toluene in a Soxhlet extractor to remove oligomers and residual catalyst. The toluene solution was concentrated and added to the methanol $(30 \mathrm{~mL})$ to give TBD25 as a dark solid (92 $\mathrm{mg}, 71.6 \%$ yield). GPC: $M_{\mathrm{n}} / \mathrm{PDI}=84.1 \mathrm{kDa} / 1.96 . \mathrm{Td}=412{ }^{\circ} \mathrm{C}$. Anal. calcd for $\left[\left(\mathrm{C}_{68} \mathrm{H}_{76} \mathrm{Cl}_{2} \mathrm{O}_{3} \mathrm{~S}_{7}\right)_{0.75}+\right.$ $\left.\left(\mathrm{C}_{78} \mathrm{H}_{92} \mathrm{Cl}_{2} \mathrm{O}_{2} \mathrm{~S}_{9}\right)_{0.25}\right]$ : C 65.99, H 6.32, S 18.74; found: C 66.57, H 6.93, S 18.02.

Synthesis of polymer TBD50: In a dry flask, $\mathrm{Pd}_{2}(\mathrm{dba})_{3} \quad\left(\begin{array}{lll}2 & \mathrm{mg}) & \text { and } \\ \text { tris }(3-\end{array}\right.$ methoxyphenyl)phosphine (4 mg) were added to a solution of M1 (57.2 mg, $0.05 \mathrm{mmol})$, M2 (47.9 $\mathrm{mg}, 0.05 \mathrm{mmol})$ and $\mathbf{M 3}(76.7 \mathrm{mg}, 0.1 \mathrm{~mol})$ in anhydrous toluene $(8 \mathrm{~mL})$ under nitrogen atmosphere and stirred at $110{ }^{\circ} \mathrm{C}$ for $16 \mathrm{~h}$. The reaction mixture was cooled to room temperature and precipitated by addition of methanol $(50 \mathrm{~mL})$. The precipitates were collected by filtration and then extracted with ethanol, hexane, dichloromethane and toluene in a Soxhlet extractor to remove oligomers and residual catalyst. The toluene solution was concentrated and added to the methanol $(30 \mathrm{~mL})$ to give TBD50 as a dark solid (103 $\mathrm{mg}$, 
77.4\% yield). GPC: $M_{\mathrm{n}} / \mathrm{PDI}=51.5 \mathrm{kDa} / 2.46 . \mathrm{Td}=418{ }^{\circ} \mathrm{C}$. Anal. calcd for $\left[\left(\mathrm{C}_{68} \mathrm{H}_{76} \mathrm{Cl}_{2} \mathrm{O}_{3} \mathrm{~S}_{7}\right)_{0.5}+\right.$ $\left.\left(\mathrm{C}_{78} \mathrm{H}_{92} \mathrm{Cl}_{2} \mathrm{O}_{2} \mathrm{~S}_{9}\right)_{0.5}\right]$ : C 65.93, H 6.44, S 19.29; found: C 64.53, H 7.20, S 18.31 .

Synthesis of polymer TBD75: In a dry flask, $\mathrm{Pd}_{2}(\mathrm{dba})_{3} \quad(2 \mathrm{mg})$ and tris(3methoxyphenyl)phosphine (4 mg) were added to a solution of M1 (85.8 $\mathrm{mg}, 0.075 \mathrm{mmol})$, M2 $(23.9 \mathrm{mg}, 0.025 \mathrm{mmol})$ and $\mathbf{M 3}(76.7 \mathrm{mg}, 0.1 \mathrm{~mol})$ in anhydrous toluene $(8 \mathrm{~mL})$ under nitrogen atmosphere and stirred at $110{ }^{\circ} \mathrm{C}$ for $16 \mathrm{~h}$. The reaction mixture was cooled to room temperature and precipitated by addition of methanol $(50 \mathrm{~mL})$. The precipitates were collected by filtration and then extracted with ethanol, hexane, dichloromethane and toluene in a Soxhlet extractor to remove oligomers and residual catalyst. The toluene solution was concentrated and added to the methanol $(30 \mathrm{~mL})$ to give TBD75 as a dark solid $(97 \mathrm{mg}$, 70.4\% yield). GPC: $M_{\mathrm{n}} / \mathrm{PDI}=57.3 \mathrm{kDa} / 2.45 . \mathrm{Td}=422{ }^{\circ} \mathrm{C}$. Anal. calcd for $\left[\left(\mathrm{C}_{68} \mathrm{H}_{76} \mathrm{Cl}_{2} \mathrm{O}_{3} \mathrm{~S}_{7}\right)_{0.25}\right.$ $\left.+\left(\mathrm{C}_{78} \mathrm{H}_{92} \mathrm{Cl}_{2} \mathrm{O}_{2} \mathrm{~S}_{9}\right)_{0.75}\right]:$ C 65.93, H 6.49, S 19.81; found: C 67.54, H 5.82, S 18.57.

Synthesis of polymer TBD100: In a dry flask, $\mathrm{Pd}_{2}(\mathrm{dba})_{3} \quad(2 \mathrm{mg})$ and tris(3methoxyphenyl)phosphine (4 mg) were added to a solution of M1 (114.4 mg, $0.1 \mathrm{mmol})$ and M3 $(76.7 \mathrm{mg}, 0.1 \mathrm{~mol})$ in anhydrous toluene $(8 \mathrm{~mL})$ under nitrogen atmosphere and stirred at $110{ }^{\circ} \mathrm{C}$ for $16 \mathrm{~h}$. The reaction mixture was cooled to room temperature and precipitated by addition of methanol $(50 \mathrm{~mL})$. The precipitates were collected by filtration and then extracted with ethanol, hexane, dichloromethane and toluene in a Soxhlet extractor to remove oligomers and residual catalyst. The toluene solution was concentrated and added to the methanol (30 $\mathrm{mL})$ to give TBD100 as a dark solid (101 mg, 70.9\% yield). GPC: $M_{\mathrm{n}} / \mathrm{PDI}=61.0 \mathrm{kDa} / 2.39$. $\mathrm{T}_{\mathrm{d}}=409{ }^{\circ} \mathrm{C}$. Anal. calcd for $\mathrm{C}_{78} \mathrm{H}_{92} \mathrm{Cl}_{2} \mathrm{O}_{2} \mathrm{~S}_{9}$ : C 65.83, H 6.66, S 20.28; found: C 64.72, H 5.93, S 18.80 .

Synthesis of polymer TBFCl-Tz: In a dry flask, $\mathrm{Pd}\left(\mathrm{PPh}_{3}\right)_{4}(5.8 \mathrm{mg})$ was added to a solution of M2 $(95.7 \mathrm{mg}, 0.1 \mathrm{mmol})$ and $\mathbf{M} 4(78.9 \mathrm{mg}, 0.1 \mathrm{~mol})$ in anhydrous toluene $(6 \mathrm{~mL})$ and DMF $(1.5 \mathrm{~mL})$ under nitrogen atmosphere and stirred at $110{ }^{\circ} \mathrm{C}$ for $16 \mathrm{~h}$. The reaction mixture was cooled to room temperature and precipitated by addition of methanol $(50 \mathrm{~mL})$. The 
precipitates were collected by filtration and then extracted with ethanol, hexane, dichloromethane and toluene in a Soxhlet extractor to remove oligomers and residual catalyst. The toluene solution was concentrated and added to the methanol $(30 \mathrm{~mL})$ to give TBFCl-Tz as a dark solid (92 $\mathrm{mg}, 73.1 \%$ yield).

Synthesis of polymer $\boldsymbol{R}-\boldsymbol{T} z$ : In a dry flask, $\mathrm{Pd}\left(\mathrm{PPh}_{3}\right)_{4}(5.8 \mathrm{mg})$ was added to a solution of $\mathbf{M} 1$ (57.2 $\mathrm{mg}, 0.05 \mathrm{mmol}), \mathbf{M} 2(47.9 \mathrm{mg}, 0.05 \mathrm{mmol})$ and $\mathbf{M} 4(78.9 \mathrm{mg}, 0.1 \mathrm{~mol})$ in anhydrous toluene $(6 \mathrm{~mL})$ and DMF $(1.5 \mathrm{~mL})$ under nitrogen atmosphere and stirred at $110^{\circ} \mathrm{C}$ for $16 \mathrm{~h}$. The reaction mixture was cooled to room temperature and precipitated by addition of methanol $(50 \mathrm{~mL})$. The precipitates were collected by filtration and then extracted with ethanol, hexane, dichloromethane and toluene in a Soxhlet extractor to remove oligomers and residual catalyst. The toluene solution was concentrated and added to the methanol $(30 \mathrm{~mL})$ to give $\mathbf{R}-\mathbf{T z}$ as a dark solid (95 $\mathrm{mg}, 70.2 \%$ yield).

Synthesis of polymer TBDCl-Tz: In a dry flask, $\mathrm{Pd}\left(\mathrm{PPh}_{3}\right)_{4}(5.8 \mathrm{mg})$ was added to a solution of M1 (114.4 mg, $0.1 \mathrm{~mol})$ and $\mathbf{M 4}(78.9 \mathrm{mg}, 0.1 \mathrm{~mol})$ in anhydrous toluene $(6 \mathrm{~mL})$ and DMF $(1.5 \mathrm{~mL})$ under nitrogen atmosphere and stirred at $110{ }^{\circ} \mathrm{C}$ for $16 \mathrm{~h}$. The reaction mixture was cooled to room temperature and precipitated by addition of methanol $(50 \mathrm{~mL})$. The precipitates were collected by filtration and then extracted with ethanol, hexane, dichloromethane and toluene in a Soxhlet extractor to remove oligomers and residual catalyst. The toluene solution was concentrated and added to the methanol $(30 \mathrm{~mL})$ to give TBDCl-Tz as a dark solid (90 mg, $62.2 \%$ yield).

Synthesis of polymer TBFCl-DTBT: In a dry flask, $\mathrm{Pd}_{2}(\mathrm{dba})_{3}(2 \mathrm{mg})$ and tris(3methoxyphenyl)phosphine (4 mg) were added to a solution of $\mathbf{M 2}(95.7 \mathrm{mg}, 0.1 \mathrm{mmol})$ and M4 $(71.9 \mathrm{mg}, 0.1 \mathrm{~mol})$ in anhydrous toluene $(6 \mathrm{~mL})$ under nitrogen atmosphere and stirred at $110{ }^{\circ} \mathrm{C}$ for $16 \mathrm{~h}$. The reaction mixture was cooled to room temperature and precipitated by addition of methanol $(50 \mathrm{~mL})$. The precipitates were collected by filtration and then extracted with ethanol, hexane, dichloromethane and toluene in a Soxhlet extractor to remove oligomers 
and residual catalyst. The toluene solution was concentrated and added to the methanol (30 $\mathrm{mL}$ ) to give TBFCl-DTBT as a dark solid (75 mg, 63.1\% yield).

Synthesis of polymer R-DTBT: In a dry flask, $\mathrm{Pd}_{2}(\mathrm{dba})_{3} \quad\left(\begin{array}{lll}2 & \mathrm{mg}\end{array}\right)$ and tris(3methoxyphenyl)phosphine (4 mg) were added to a solution of M1 (57.2 mg, $0.05 \mathrm{mmol}), \mathbf{M 2}$ (47.9 $\mathrm{mg}, 0.05 \mathrm{mmol})$ and $\mathbf{M} 4(71.9 \mathrm{mg}, 0.1 \mathrm{~mol})$ in anhydrous toluene $(6 \mathrm{~mL})$ under nitrogen atmosphere and stirred at $110{ }^{\circ} \mathrm{C}$ for $16 \mathrm{~h}$. The reaction mixture was cooled to room temperature and precipitated by addition of methanol $(50 \mathrm{~mL})$. The precipitates were collected by filtration and then extracted with ethanol, hexane, dichloromethane and toluene in a Soxhlet extractor to remove oligomers and residual catalyst. The toluene solution was concentrated and added to the methanol $(30 \mathrm{~mL})$ to give R-DTBT as a dark solid $(88 \mathrm{mg}$, $68.6 \%$ yield).

Synthesis of polymer TBDCl-DTBT: In a dry flask, $\mathrm{Pd}_{2}(\mathrm{dba})_{3}(2 \mathrm{mg})$ and tris(3methoxyphenyl)phosphine (4 mg) were added to a solution of M1 (114.4 mg, $0.1 \mathrm{~mol}$ ) and M4 (71.9 mg, $0.1 \mathrm{~mol})$ in anhydrous toluene $(6 \mathrm{~mL})$ under nitrogen atmosphere and stirred at $110{ }^{\circ} \mathrm{C}$ for $16 \mathrm{~h}$. The reaction mixture was cooled to room temperature and precipitated by addition of methanol $(50 \mathrm{~mL})$. The precipitates were collected by filtration and then extracted with ethanol, hexane, dichloromethane and toluene in a Soxhlet extractor to remove oligomers and residual catalyst. The toluene solution was concentrated and added to the methanol (30 $\mathrm{mL}$ ) to give TBDCI-DTBT as a dark solid (92 $\mathrm{mg}, 66.9 \%$ yield).

\section{Measurements and Characterizations}

The ${ }^{1} \mathrm{H}$ NMR and ${ }^{13} \mathrm{C}$ NMR spectra of the monomers were recorded on a Bruker AVANCEIII 600 Spectrometer with $\mathrm{CDCl}_{3}$ as the solvent. The molecular weight and polydispersity index (PDI) of the polymers were determined by high-temperature gel permeation chromatography (GPC) using 1, 3, 5-trichlorobenzene as the eluent and polystyrene as the standard. Thermal gravimetric analysis (TGA) measurement was performed by STA-409 at a 
heating rate of $10{ }^{\circ} \mathrm{C} / \mathrm{min}$ under nitrogen atmosphere. The UV-vis absorption spectra of the polymers were recorded using a Hitachi U-4100 spectrophotometer. PL spectra were measured using a Fluoromax-4 fluorescence spectrometer. Cyclic voltammetry (CV) measurement was recorded on a CHI660D electrochemical workstation with a three-electrode system (a glassy carbon working electrode, a saturated calomel electrode (SCE) as reference electrode and a platinum wire counter electrode) using a scan rate of $100 \mathrm{mV} / \mathrm{s}$ with a nitrogen saturated solution of $0.1 \mathrm{M}$ tetrabutylammonium hexafluorophosphate $\left(\mathrm{Bu}_{4} \mathrm{NPF}_{6}\right)$ in acetonitrile. Transmission electron microscopy (TEM) measurement was performed by using a HITACHI H-7650 electron microscope with an acceleration voltage of $100 \mathrm{kV}$. Grazing incidence wide-angle X-ray scattering (GIWAXS) and grazing incidence small-angle X-ray scattering (GISAXS) patterns were acquired by beamline BL16B1 at Shanghai Synchrotron Radiation Facility (SSRF). The X-ray wavelength was chosen as $0.124 \mathrm{~nm}(E=10 \mathrm{keV})$, and the incidence angle was set to 0.15 degree. For GIWAXS and GISAXS experiments, the sample to detector distance was $211.16 \mathrm{~mm}$ and $5104.51 \mathrm{~mm}$.

TA Spectroscopy measurements: The charge photogeneration and recombination dynamics of polymer: IT-4F systems were studied using Femtosecond Transient Absorption (TA) spectroscopy, where the system used is according to the design described in previous literature. ${ }^{5}$ Here all the polymer:fullerene blends under vacuum were excited by $100 \mathrm{fs}, 500$ nm laser pulses, produced by an optical parametric amplifier (TOPAS) which are chopped at 1.5 KHz. The broadband probe pulses are generated by focusing a small fraction of the 800 nm fundamental into an undoped YAG crystal. The polarization of the pump beam is set at the magic angle (54.70) with respect to that of the probe beam in order to avoid the orientational or polarization effects. After the transmission through the sample, the probe continuum is spectrally dispersed and collected (visible and near IR components) simultaneously by two cameras. The differential transmission signal is calculated from the transmitted probe pulses corresponding to the pump on versus off. A retroreflector on a 
motorized translational stage is used to vary the relative delay between the pump and the probe pulses. The result of a typical experiment is a 3-dimensional data set; where each column corresponds to a full spectrum at a certain time and each raw corresponds to the kinetics at different wavelengths.

Electroluminescence experiments. For electroluminescence (EL) measurement, the blend and single component devices were forward biased by a Keithley 2400 source measure unit with $50 \mathrm{~mA}$ steady current injection, if not stated otherwise. The large injecting current compensates the morphology or trap induced non-radiative process, and reveals the potential radiative capability of materials. The emitted photons were captured by a standard lamp calibrated high-sensitivity spectrometer (QE Pro, Ocean Optics) equipped with a cooled Hamamatsu CCD array. Number of photons collected by light guide or detector is highly sensitive to distance and incident angle, we used a customized tiny integrating sphere to collect emitted photons in all direction while maintaining incident EL intensity as high possible, a reference lamp was also employed to calibrate the set-up. The electroluminescence external quantum efficiency $\left(\mathrm{EQ} E_{\mathrm{EL}}\right)$ was calculated by wavelength integrated photons divide by injected electrons.

\section{Device Fabrication and Testing}

PSCs devices were fabricated with a conventional device structure of ITO/PEDOT:PSS/active layer/PDINO/Al. The ITO-coated glass substrates were sonicated successively with detergent, deionized water, acetone and isopropanol, and dried with nitrogen flow. Immediately prior to device fabrication, the substrates were cleaned by oxygen plasma for $5 \mathrm{~min}$. And then, the PEDOT:PSS layer was spin-coated onto the ITO and annealing at $160{ }^{\circ} \mathrm{C}$ for $10 \mathrm{~min}$. The polymer/ITIC solutions were stirred at room temperature before spin-coating. And then, the polymer/ITIC (different weight ratio) solution was spin-coated on the top of PEDOT:PSS from the chlorobenzene $(\mathrm{CB})$ solution. Then PDINO solution (in $\mathrm{CH}_{3} \mathrm{OH}$ ) was spin-coated as electron transfer layer. Finally, aluminum $(100 \mathrm{~nm})$ was evaporated onto the active layer at a 
vacuum of $\sim 2 \times 10^{-4} \mathrm{~Pa}$ to form the top electrode. The effective area of the device is $0.1 \mathrm{~cm}^{2}$. The current-voltage $(\mathrm{J}-\mathrm{V})$ characteristics were measured with a Keithley 2420 source measurement unit. The PSCs were measured under an irradiation intensity of $100 \mathrm{~mW} / \mathrm{cm}^{2}$ (AM 1.5 G) by a Newport solar simulator. The EQE spectra were analyzed using a certified Newport IPCE measurement system. The hole and electron mobilities were calculated using the space charge limited current (SCLC) model with a device configuration of ITO/PEDOT:PSS/active layer/ $\mathrm{MoO}_{3} / \mathrm{Al}$ and $\mathrm{ITO} / \mathrm{ZnO} /$ active layer/PDINO/Al, respectively, where the current density is calculated by:

$$
J=9 \varepsilon_{o} \varepsilon_{r} \mu V^{2} /\left(8 L^{3}\right)
$$

where $J$ stands for current density, $\varepsilon_{o}$ is the permittivity of free space, $\varepsilon_{r}$ is the relative dielectric constant of the transport medium, $\mu$ is the hole mobility, $V$ is the voltage drop across the device $\left(V=V_{\mathrm{appl}}-V_{\mathrm{bi}}-V_{\mathrm{RS}}\right.$, where $V_{\text {appl }}$ is the applied voltage to the device, $V_{\mathrm{bi}}$ is the built-in voltage due to the difference in work function of the two electrodes, and $V_{\mathrm{RS}}$ is the voltage drop due to series resistance across the electrodes), and $\mathrm{L}$ is the thickness of the active layer.

\section{Analysis model for GISAXS}

To quantify and compare the phase separation in the non-fullerene photovoltaic blends, a universal model expressed in Equation 1 is used to fit the 1D GISAXS profile in the low- $q$ range $\left(0.1-0.5 \mathrm{~nm}^{-1}\right)$.

$$
I(q)=\frac{\mathrm{A}_{1}}{\left[1+(q \xi)^{2}\right]^{2}}+\mathrm{A}_{2}\langle P(q, R)\rangle S(q, R, \eta, D)+B
$$

The first term is the so-called Debye-Anderson-Brumberger (DAB) term ${ }^{6}$, where $q$ is the scattering wave vector, $\mathrm{A}_{1}$ and $\mathrm{A}_{2}$ are independent fitting parameter, and $\xi$ is the average correlation length of polymer domain. In the second term, $P(q, R)$ is the form factor modeled 
of IT-4F, and $\mathrm{S}(q, R, \eta, D)$ is the fractal structure factor, which describes the interaction between primary particles in this fractal-like aggregation system expressed in Equation $2^{7}$.

$$
S(\mathrm{q})=1+\frac{\sin \left[(D-1) \tan ^{-1}(\mathrm{q} \eta)\right]}{(q R)^{D}} \frac{D \Gamma(D-1)}{\left[1+\frac{1}{(\mathrm{q} \eta)^{2}}\right]^{(D-1) / 2}}
$$

where $\mathrm{R}$ is the mean spherical radius of primary particles, and $\eta$ is the correlation length of fractal-like network, and D is the fractal dimension of the structure. The average domain size of the aggregated cluster phases is approximately characterized by the Guinier radius $\left(R_{\mathrm{g}}\right)$ of the network, where $R_{\mathrm{g}}=\sqrt{\frac{D(D+1)}{2} \eta}$. In non-fullerene systems, the DAB term is used to model the scattering of dispersive IT-4F and the second term represents the contribution of fractallike aggregations of IT-4F. $\xi$ is traditionally used to estimate the size of domain where acceptor dispersed in polymer, which can be identified from the "shoulder" occur in the 1D GISAXS profile. 


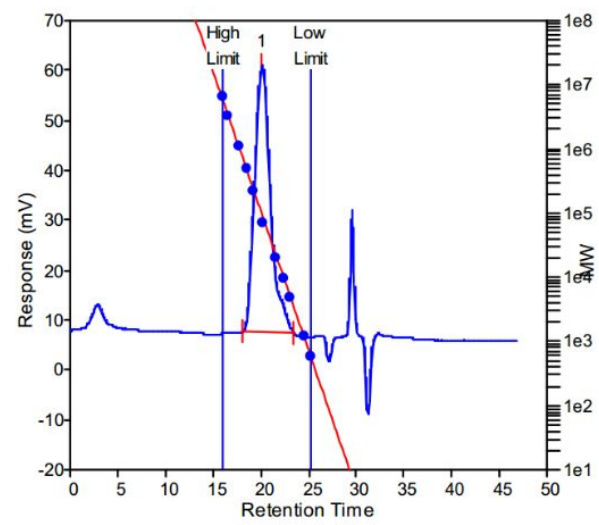

Distribution Plots

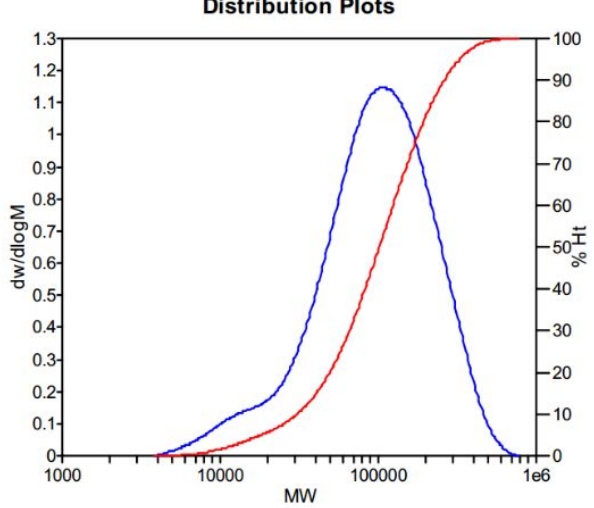

TBD25

MW Averages

$\begin{array}{llllllll}M p & M n & M w & M z & M z+1 & M v & \text { PD }\end{array}$

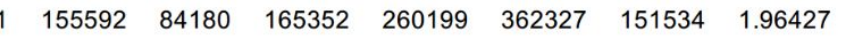

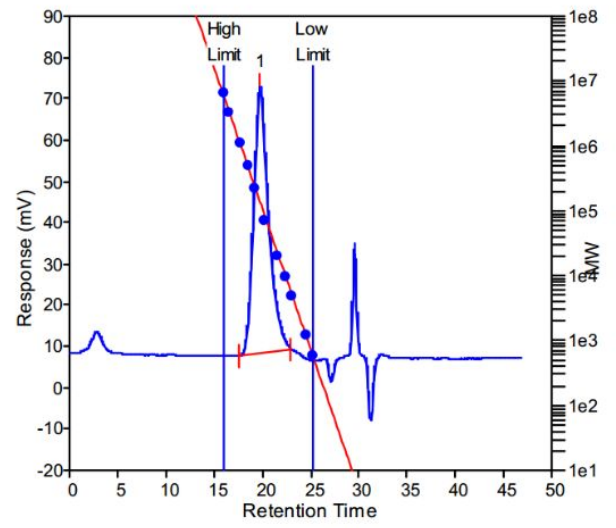

Distribution Plots

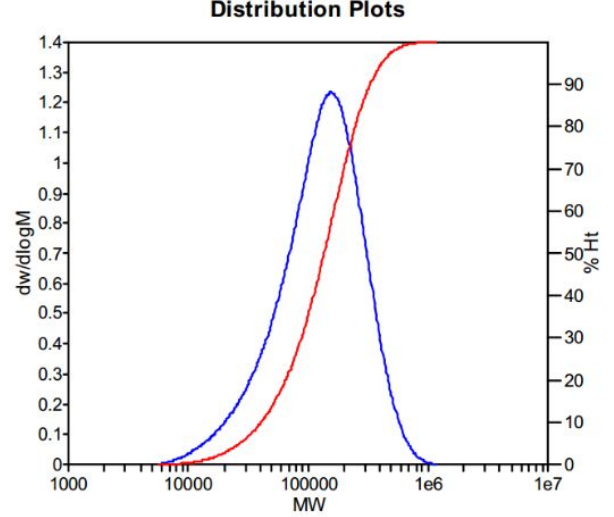

TBD50 MW Averages
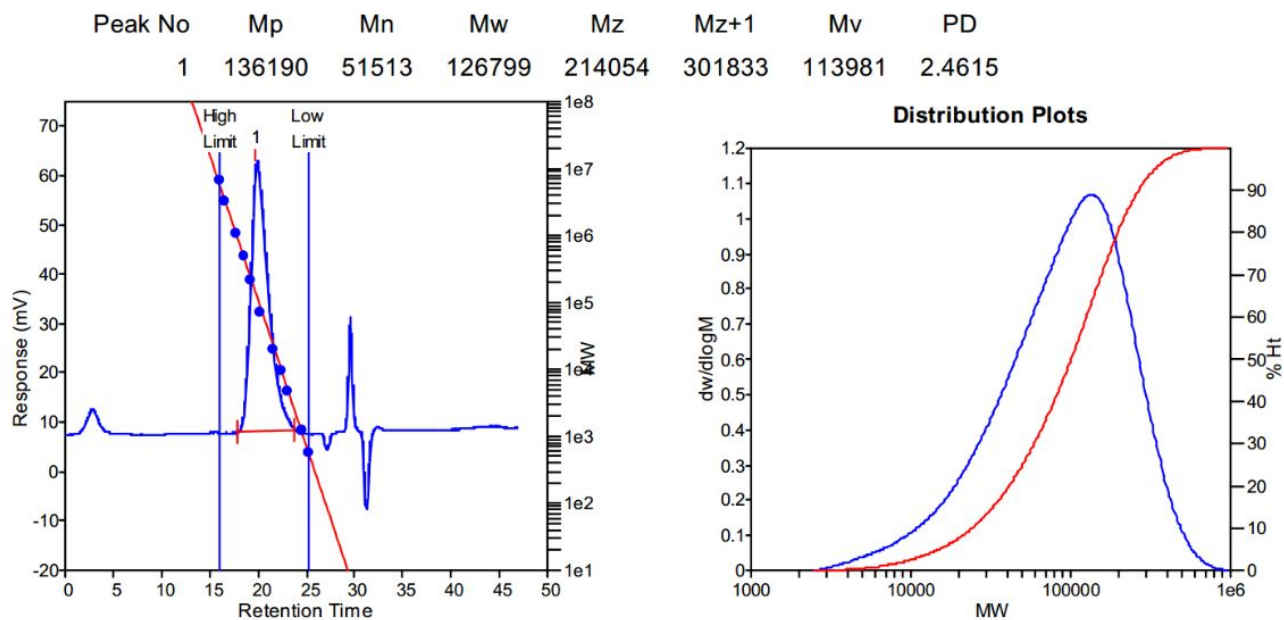


\section{MW Averages}

$\begin{array}{rccccccc}\text { Peak No } & M p & M n & M w & M z & M z+1 & M v & \text { PD } \\ 1 & 145568 & 57297 & 140397 & 238818 & 338624 & 126066 & 2.45034\end{array}$
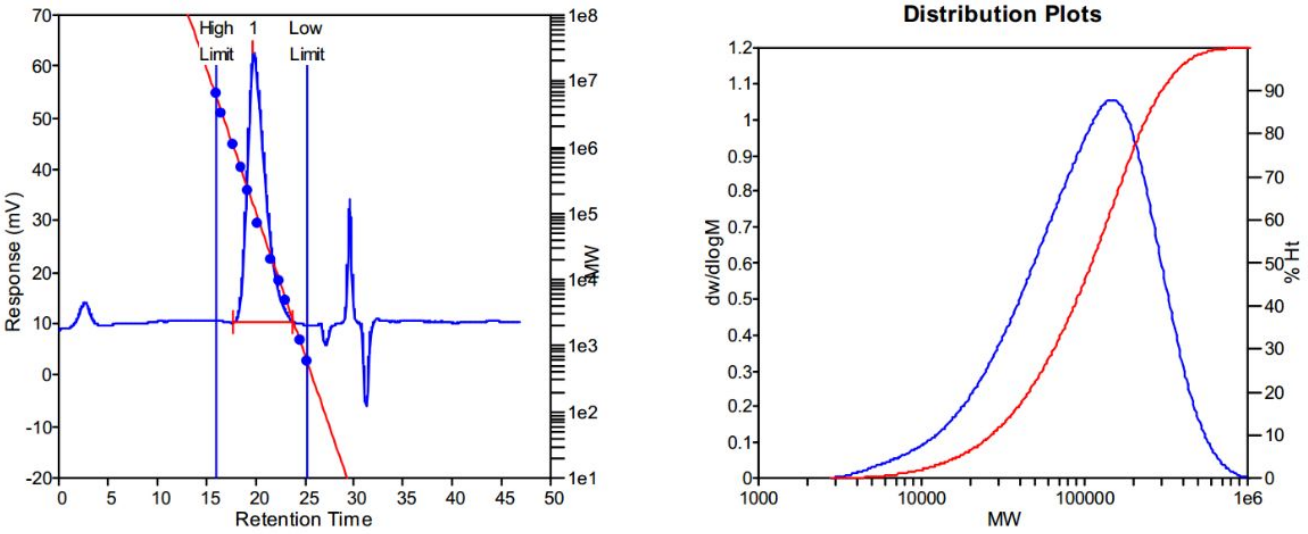

\section{TBD100}
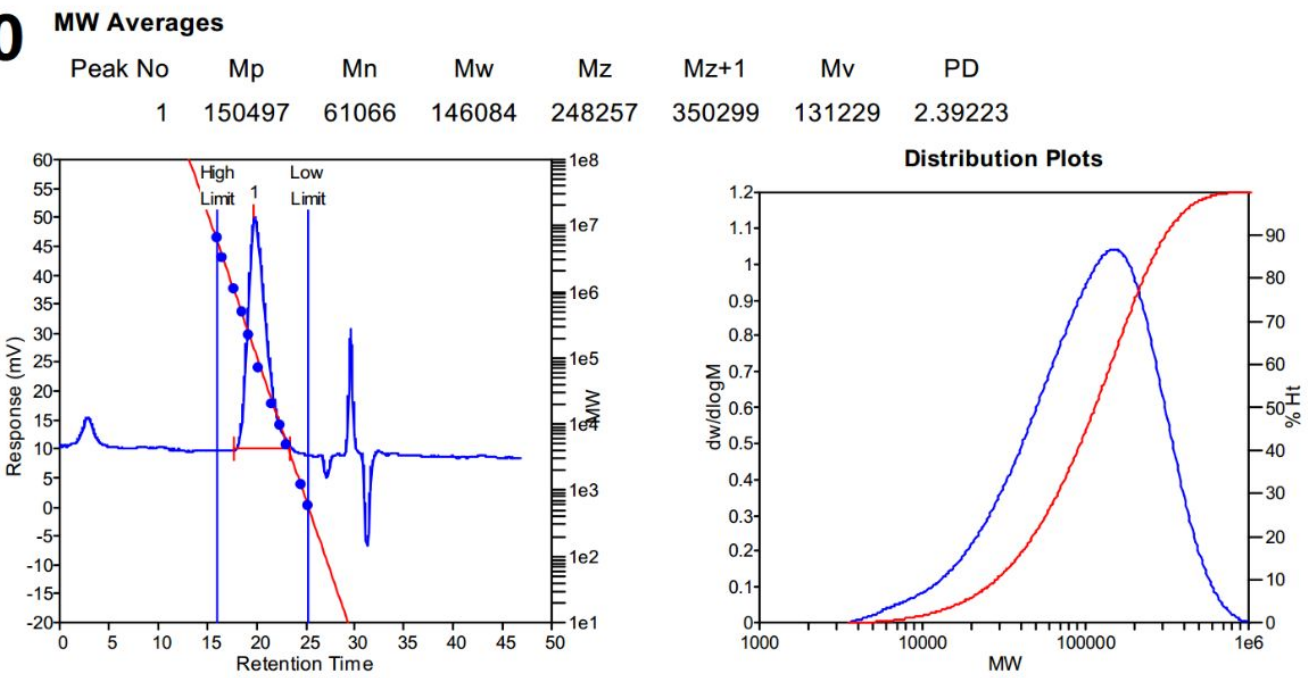

Figure S1. The GPC diagrams of the target polymers using trichlorobenzene as eluent.

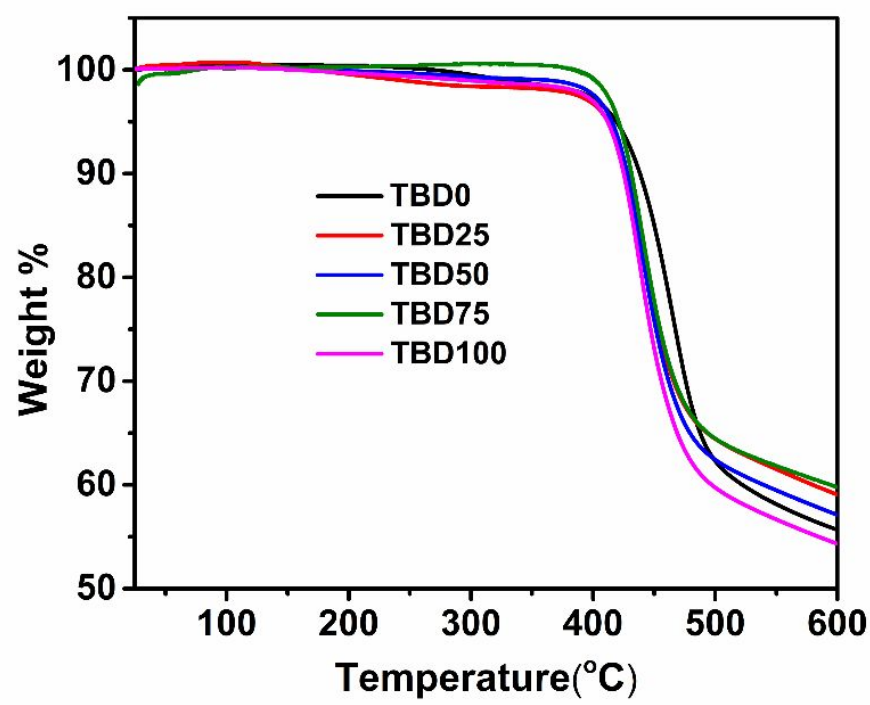

Figure S2. The thermogravimertic analysis (TGA) of the target polymers. 

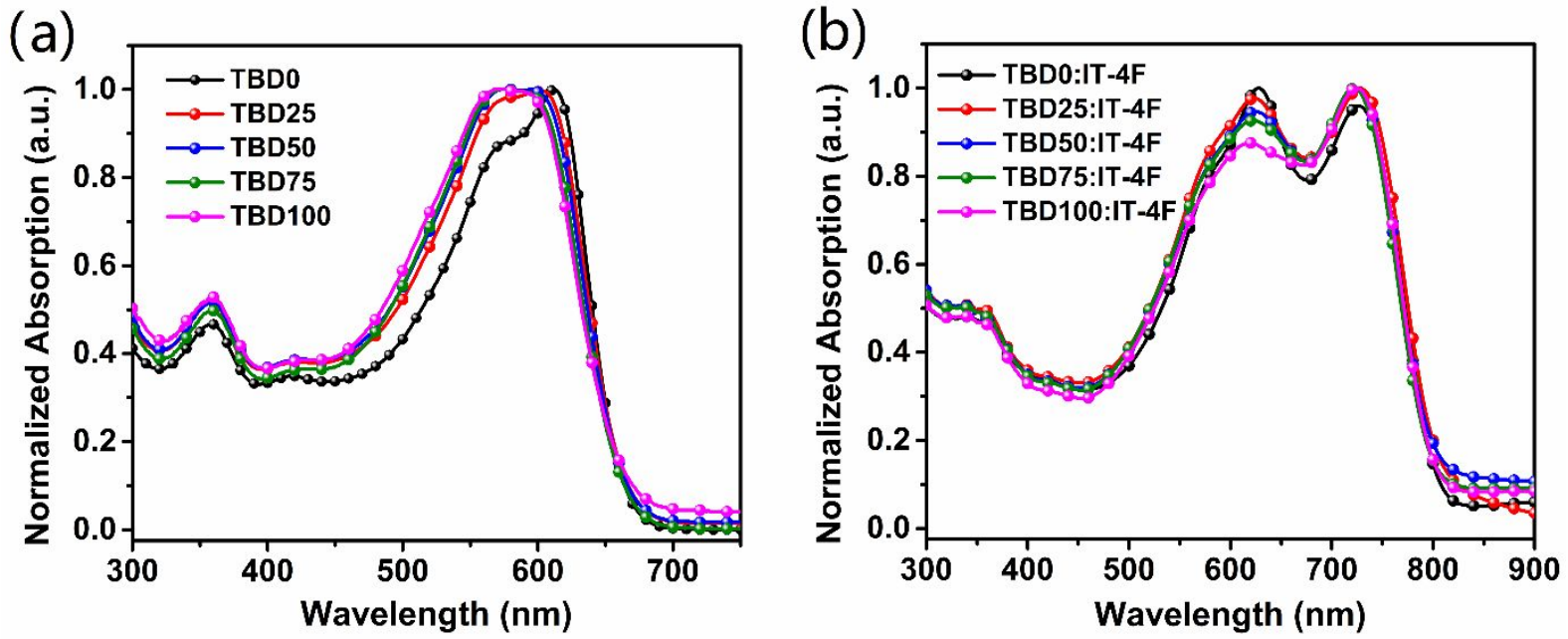

Figure S3. Normalized ultraviolet-visible absorption of the corresponding (a) polymers in solution and (b) blend films

Table S1. Summary of optical properties of polymers

\begin{tabular}{ccccccccc}
\hline Polymers & $M \mathrm{n}(\mathrm{kDa})$ & PDI & $\lambda_{\max }{ }^{\text {sol }}(\mathrm{nm})$ & $\lambda_{\max }{ }^{\text {film }}(\mathrm{nm})$ & $\lambda_{\text {edge }}(\mathrm{nm})$ & $\mathrm{E}_{\mathrm{g}}{ }^{\text {opt }}(\mathrm{eV})$ & $\mathrm{HOMO}^{\mathrm{a}}(\mathrm{eV})$ & $\mathrm{LUMO}(\mathrm{eV})^{\mathrm{a}}$ \\
\hline TBD0 & 60.4 & 2.10 & 530 & 536 & 663 & 1.87 & -5.48 & -3.62 \\
TBD25 & 84.1 & 1.96 & 532 & 542 & 664 & 1.87 & -5.49 & -3.63 \\
TBD50 & 51.5 & 2.46 & 533 & 543 & 666 & 1.86 & -5.50 & -3.65 \\
TBD75 & 57.3 & 2.45 & 533 & 544 & 664 & 1.87 & -5.50 & -3.65 \\
TBD100 & 61.1 & 2.39 & 533 & 548 & 669 & 1.85 & -5.51 & -3.65 \\
\hline
\end{tabular}

aestimated from CV measurement.
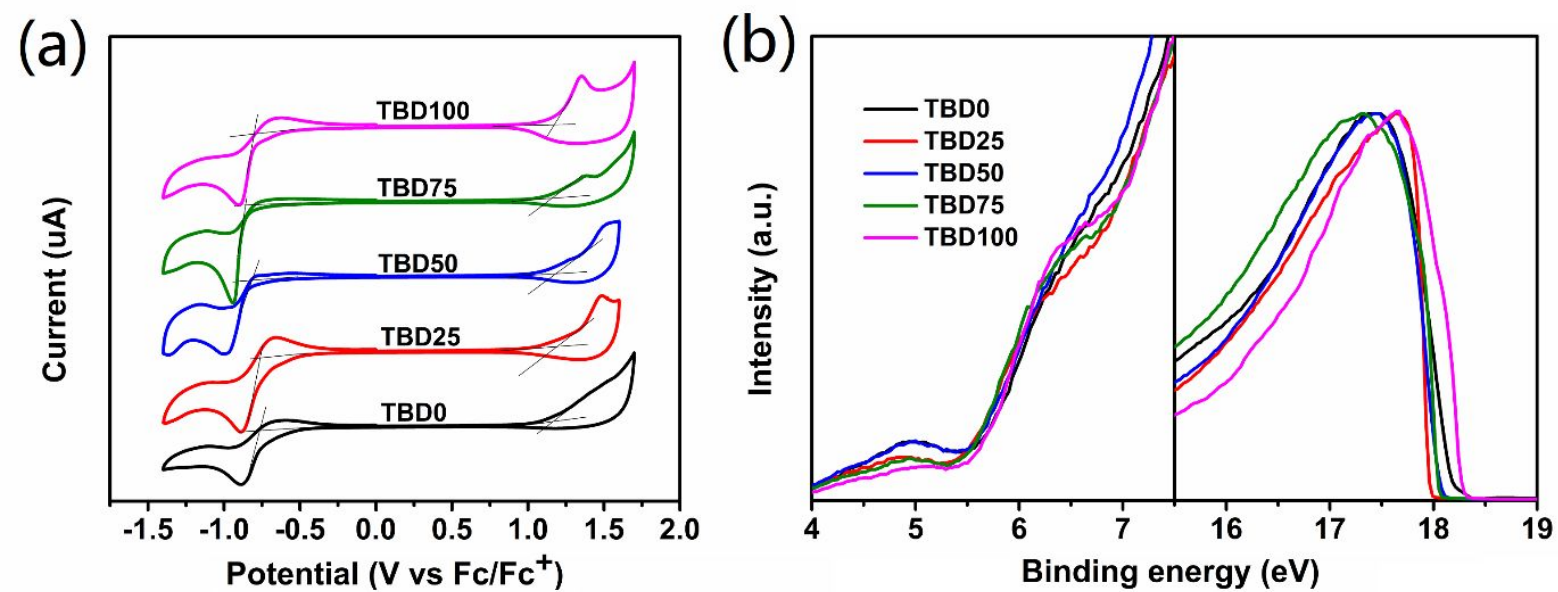

Figure S4. (a) Electrochemical cyclic voltammogram curves of the target polymers. (b)

Ultraviolet photoelectron spectroscopy (UPS) of the polymers. 


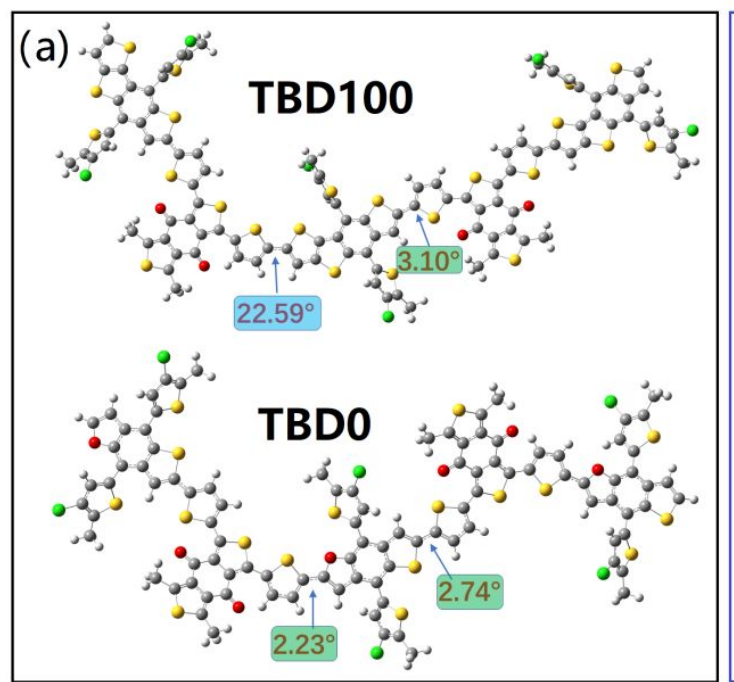

(b) Terpolymer
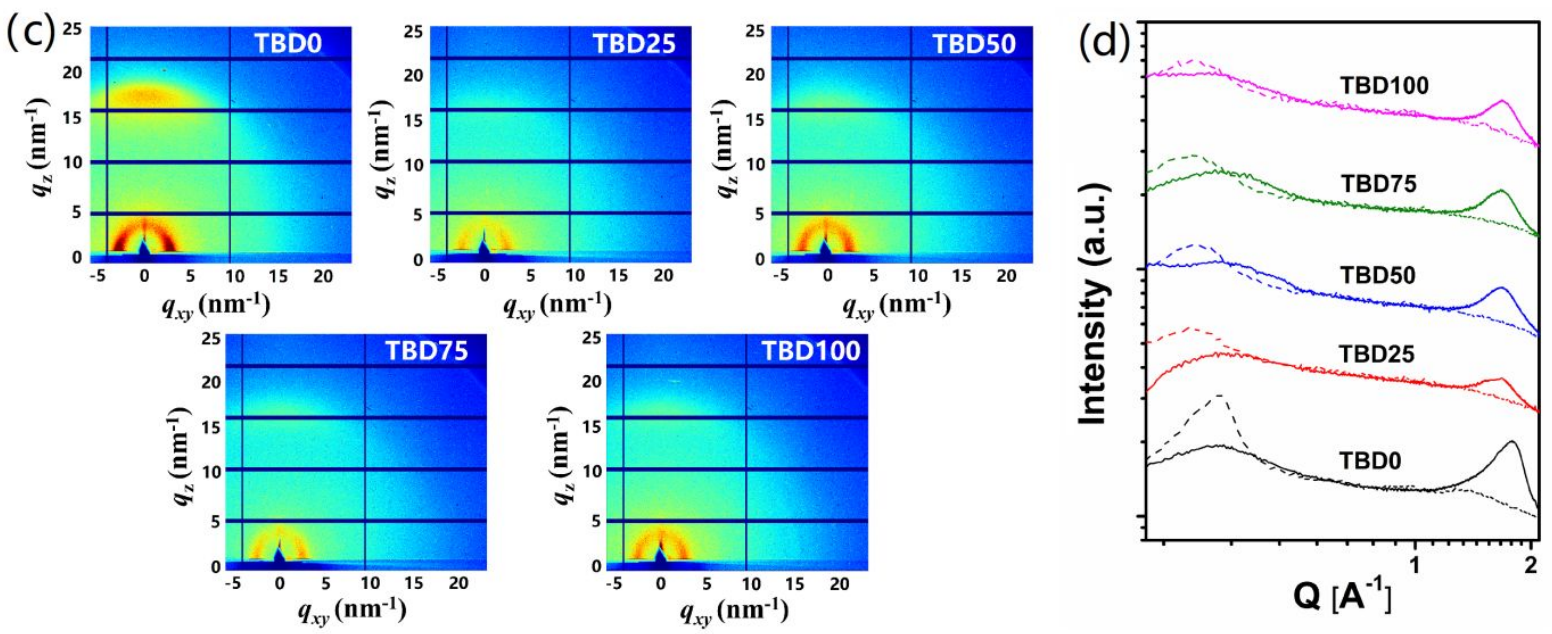

Figure S5 Chemical geometry of the molecular models for (a) TBD100 and TBD0. (b) TBDx $(25,50,75$, TBD moiety with different orientation inserting into the polymer TBD0). (c) The 2D-GIWAXS profiles and (d) the related in-plane and out-of-plane line-cut profiles of the neat polymers.

Table S2. Optimal photovoltaic parameters of solar cells under standard AM 1.5G illumination, $100 \mathrm{~mW} \mathrm{~cm}^{-2}$

\begin{tabular}{cccccc}
\hline Blend & D/A $(\mathrm{w} / \mathrm{w})$ & $V_{\mathrm{OC}}(\mathrm{V})$ & $J_{\mathrm{SC}}\left(\mathrm{mA} \mathrm{cm}^{-2}\right)$ & $\mathrm{FF}(\%)$ & $\begin{array}{c}\text { Highest PCE } \\
(\%)\end{array}$ \\
\hline TBD0:IT-4F & $1: 1^{\mathrm{a}}$ & $0.896 \pm 0.006$ & $17.1 \pm 0.2$ & $59.1 \pm 1.4$ & 9.5 \\
TBD0:IT-4F & $1: 1^{\mathrm{b}}$ & $0.887 \pm 0.005$ & $18.3 \pm 0.3$ & $63.1 \pm 1.3$ & 10.6 \\
TBD0:IT-4F & $1: 0.8^{\mathrm{c}}$ & $0.865 \pm 0.005$ & $17.7 \pm 0.4$ & $68.5 \pm 1.7$ & 10.9 \\
TBD0:IT-4F & $1: 1.25^{\mathrm{c}}$ & $0.865 \pm 0.004$ & $18.6 \pm 0.3$ & $70.6 \pm 1.0$ & 11.6 \\
TBD0:IT-4F & $1: 1^{\mathrm{c}}$ & $0.867 \pm 0.005$ & $18.8 \pm 0.3$ & $70.8 \pm 1.5$ & 12.0 \\
\hline
\end{tabular}




\begin{tabular}{|c|c|c|c|c|c|}
\hline TBD25:IT-4F & $1: 1^{\mathrm{a}}$ & $0.906 \pm 0.005$ & $17.9 \pm 0.3$ & $65.8 \pm 1.5$ & 11.0 \\
\hline TBD25:IT-4F & $1: 1^{\mathrm{b}}$ & $0.890 \pm 0.006$ & $18.9 \pm 0.3$ & $66.9 \pm 1.4$ & 11.7 \\
\hline TBD25:IT-4F & $1: 0.8^{c}$ & $0.874 \pm 0.004$ & $20.2 \pm 0.4$ & $70.5 \pm 0.9$ & 12.9 \\
\hline TBD25:IT-4F & $1: 1.25^{\mathrm{c}}$ & $0.877 \pm 0.004$ & $20.0 \pm 0.3$ & $73.8 \pm 1.2$ & 13.4 \\
\hline TBD25:IT-4F & $1: 1^{\mathrm{c}}$ & $0.878 \pm 0.004$ & $20.3 \pm 0.3$ & $73.6 \pm 1.3$ & 13.5 \\
\hline TBD50:IT-4F & $1: 1^{\mathrm{a}}$ & $0.914 \pm 0.005$ & $18.1 \pm 0.3$ & $66.4 \pm 1.2$ & 11.3 \\
\hline TBD50:IT-4F & $1: 1^{\mathrm{b}}$ & $0.896 \pm 0.005$ & $20.1 \pm 0.3$ & $68.2 \pm 1.2$ & 12.7 \\
\hline TBD50:IT-4F & $1: 0.8^{c}$ & $0886 \pm 0.004$ & $20.7 \pm 0.3$ & $74.0 \pm 1.0$ & 13.9 \\
\hline TBD50:IT-4F & $1: 1.25^{\mathrm{c}}$ & $0.881 \pm 0.003$ & $20.4 \pm 0.2$ & $73.5 \pm 1.1$ & 13.5 \\
\hline TBD50:IT-4F & $1: 1^{\mathrm{c}}$ & $0.890 \pm 0.003$ & $20.6 \pm 0.3$ & $75.4 \pm 1.5$ & 14.2 \\
\hline TBD75IT-4F & $1: 1^{\mathrm{a}}$ & $0.912 \pm 0.005$ & $17.9 \pm 0.4$ & $64.6 \pm 0.8$ & 10.9 \\
\hline TBD75:IT-4F & $1: 1^{\mathrm{b}}$ & $0.897 \pm 0.006$ & $19.3 \pm 0.2$ & $66.8 \pm 1.1$ & 11.9 \\
\hline TBD75:IT-4F & $1: 0.8^{c}$ & $0.888 \pm 0.005$ & $20.0 \pm 0.2$ & $71.6 \pm 1.2$ & 13.1 \\
\hline TBD75:IT-4F & $1: 1.25^{\mathrm{c}}$ & $0.884 \pm 0.005$ & $20.2 \pm 0.3$ & $71.4 \pm 1.0$ & 13.1 \\
\hline TBD75:IT-4F & $1: 1^{\mathrm{c}}$ & $0.885 \pm 0.003$ & $20.5 \pm 0.2$ & $72.6 \pm 1.6$ & 13.6 \\
\hline TBD100:IT-4F & $1: 1^{\mathrm{a}}$ & $0.910 \pm 0.004$ & $18.0 \pm 0.4$ & $62.2 \pm 1.2$ & 10.6 \\
\hline TBD100:IT-4F & $1.1^{\mathrm{d}}$ & $0.886 \pm 0.005$ & $18.7 \pm 0.3$ & $65.0 \pm 1.5$ & 11.2 \\
\hline TBD100:IT-4F & $1: 0.8^{c}$ & $0.872 \pm 0.005$ & $19.5 \pm 0.3$ & $70.0 \pm 1.0$ & 12.3 \\
\hline TBD100:IT-4F & $1: 1.25^{\mathrm{c}}$ & $0.871 \pm 0.004$ & $19.8 \pm 0.3$ & $71.7 \pm 1.2$ & 12.8 \\
\hline TBD100:IT-4F & $1: 1^{\mathrm{c}}$ & $0.880 \pm 0.004$ & $19.8 \pm 0.4$ & $71.4 \pm 1.4$ & 13.0 \\
\hline
\end{tabular}

a The as-cast devices. ${ }^{\mathrm{b}}$ Thermal annealed at $110{ }^{\circ} \mathrm{C}$ for 10 minutes. ${ }^{\mathrm{c}}$ Thermal annealing at $110^{\circ} \mathrm{C}$ and DIO $0.5 \%(\mathrm{v} / \mathrm{v})$. 

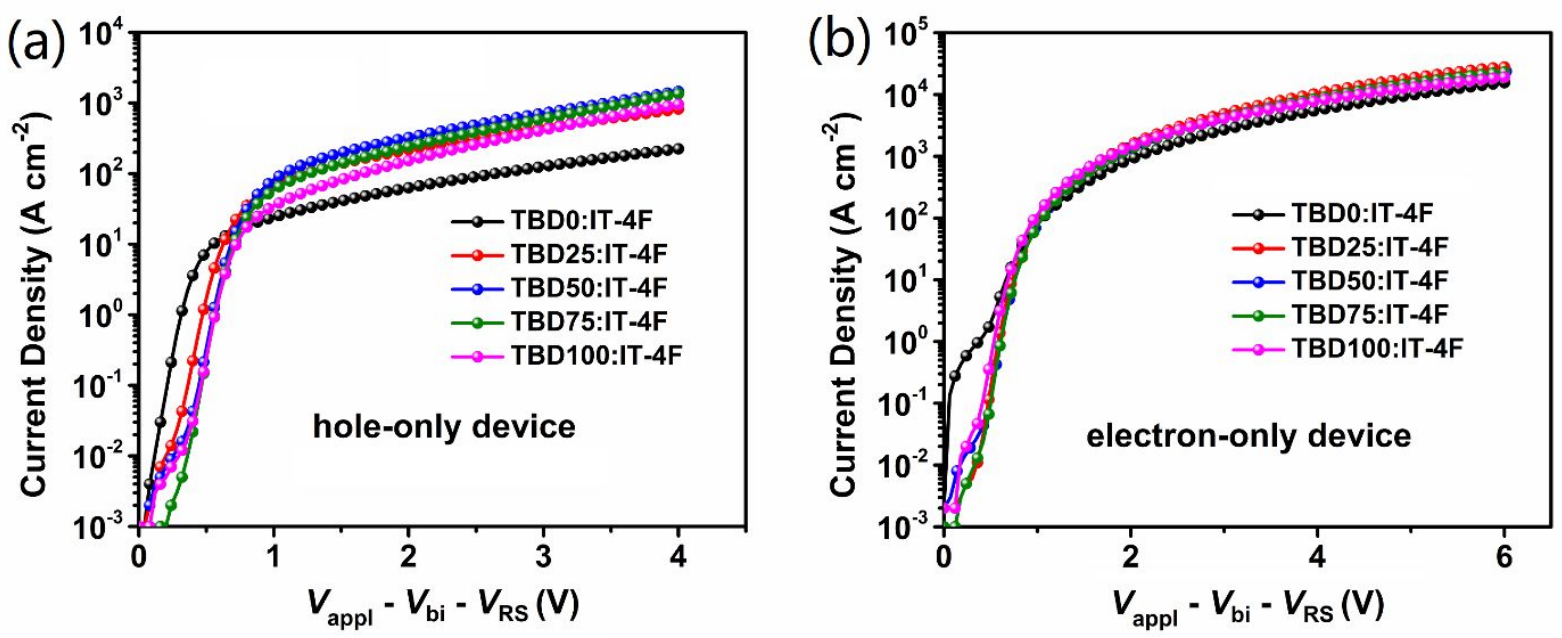

Figure S6 SCLC curves for (a) hole-only and (b) electron-only devices based on polymer:IT4F blend films.

Table S3. Hole and electron mobilities obtained by SCLC method

\begin{tabular}{ccc}
\hline \multirow{2}{*}{ Blend } & $\mu_{\mathrm{h}}$ & \multicolumn{2}{c}{$\mu_{\mathrm{e}}$} \\
\cline { 2 - 3 } & \multicolumn{2}{c}{$10^{-4} \mathrm{~cm}^{2} \mathrm{~V}^{-1} \mathrm{~s}^{-1}$} \\
\hline TBD0:IT-4F & 0.3 & 3.2 \\
TBD25:IT-4F & 2.2 & 6.0 \\
TBD50:IT-4F & 2.6 & 5.3 \\
TBD75:IT-4F & 1.4 & 6.9 \\
TBD100:IT-4F & 0.9 & 4.2 \\
\hline
\end{tabular}

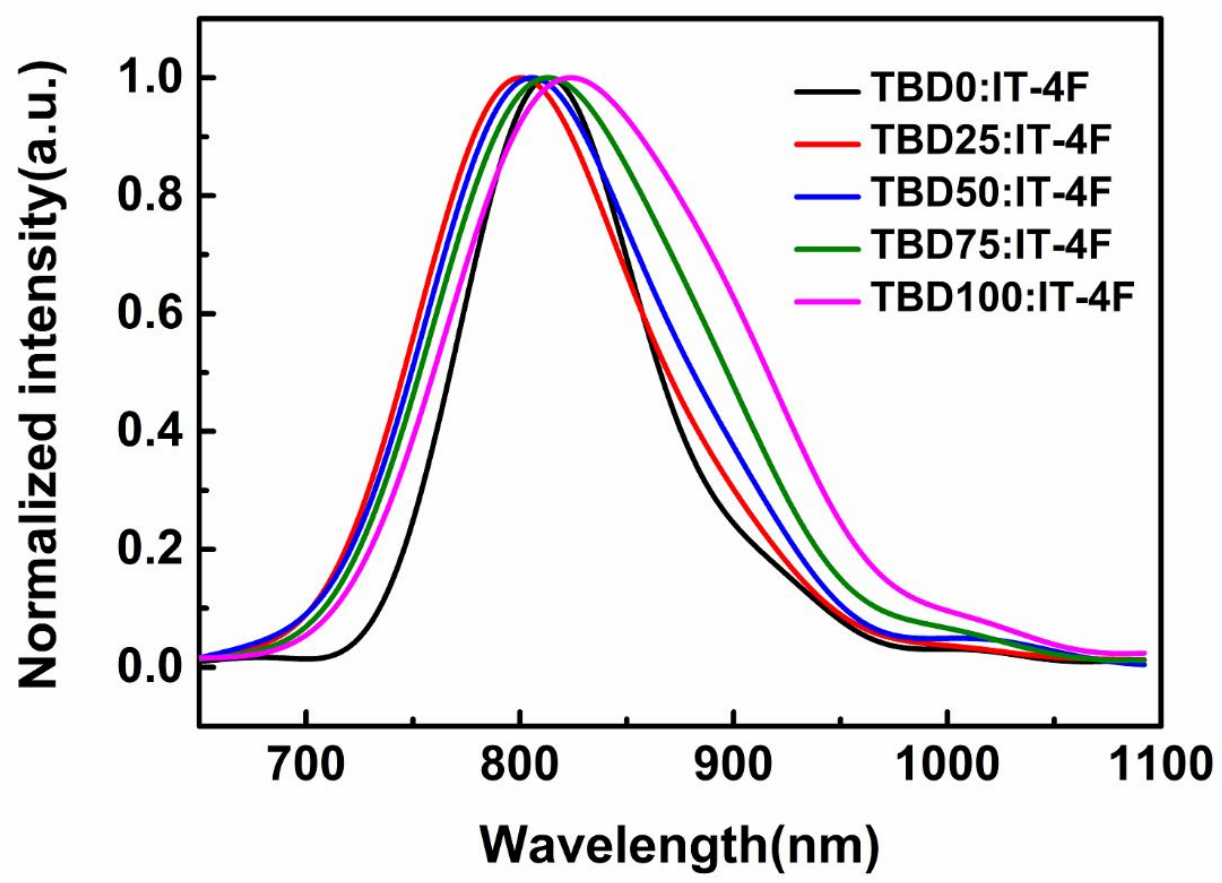

Figure S7. Electroluminescence spectra of the corresponding polymers blended with IT-4F. 

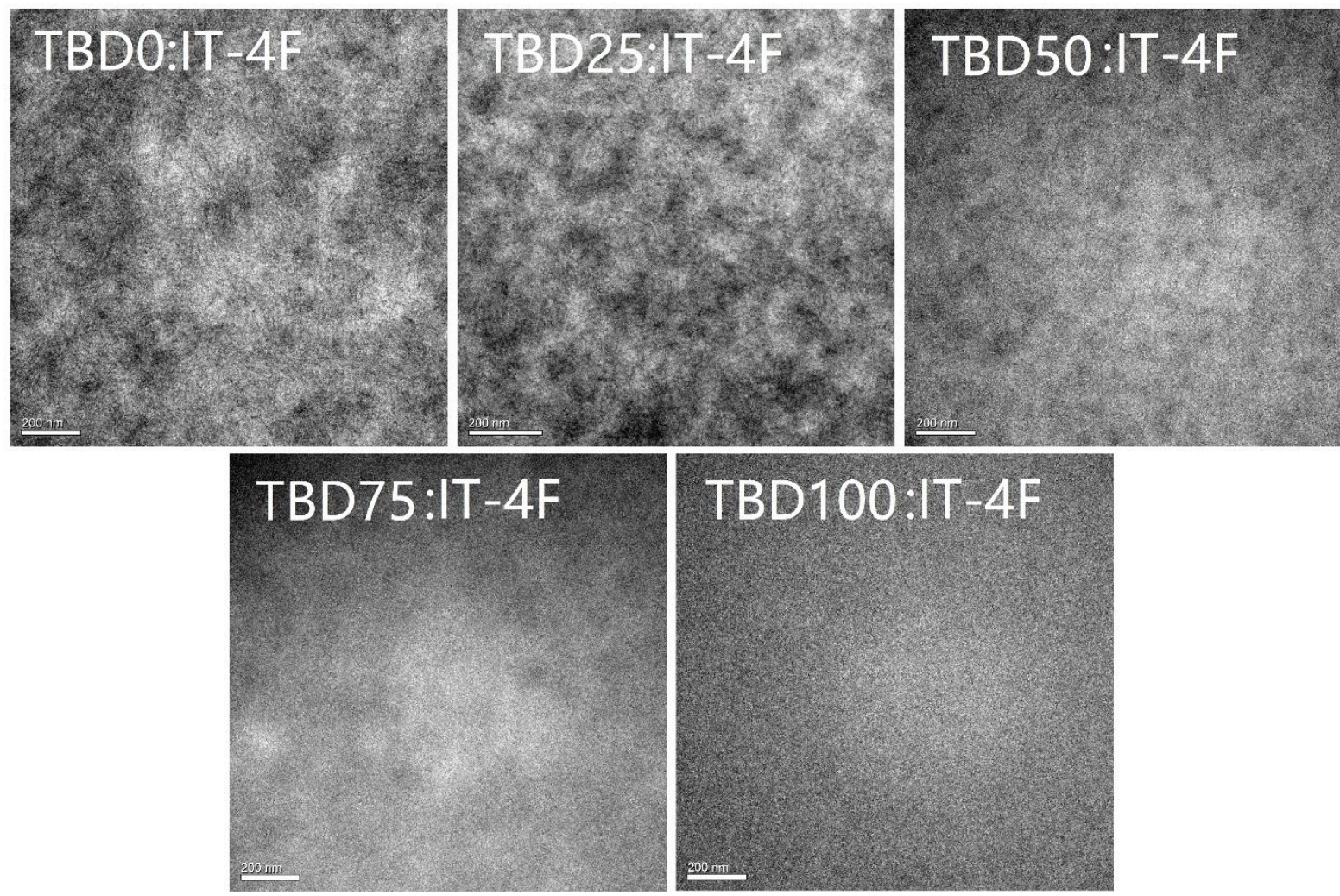

Figure S8. TEM images of TBDx/IT-4F blend films in the optimized condition.
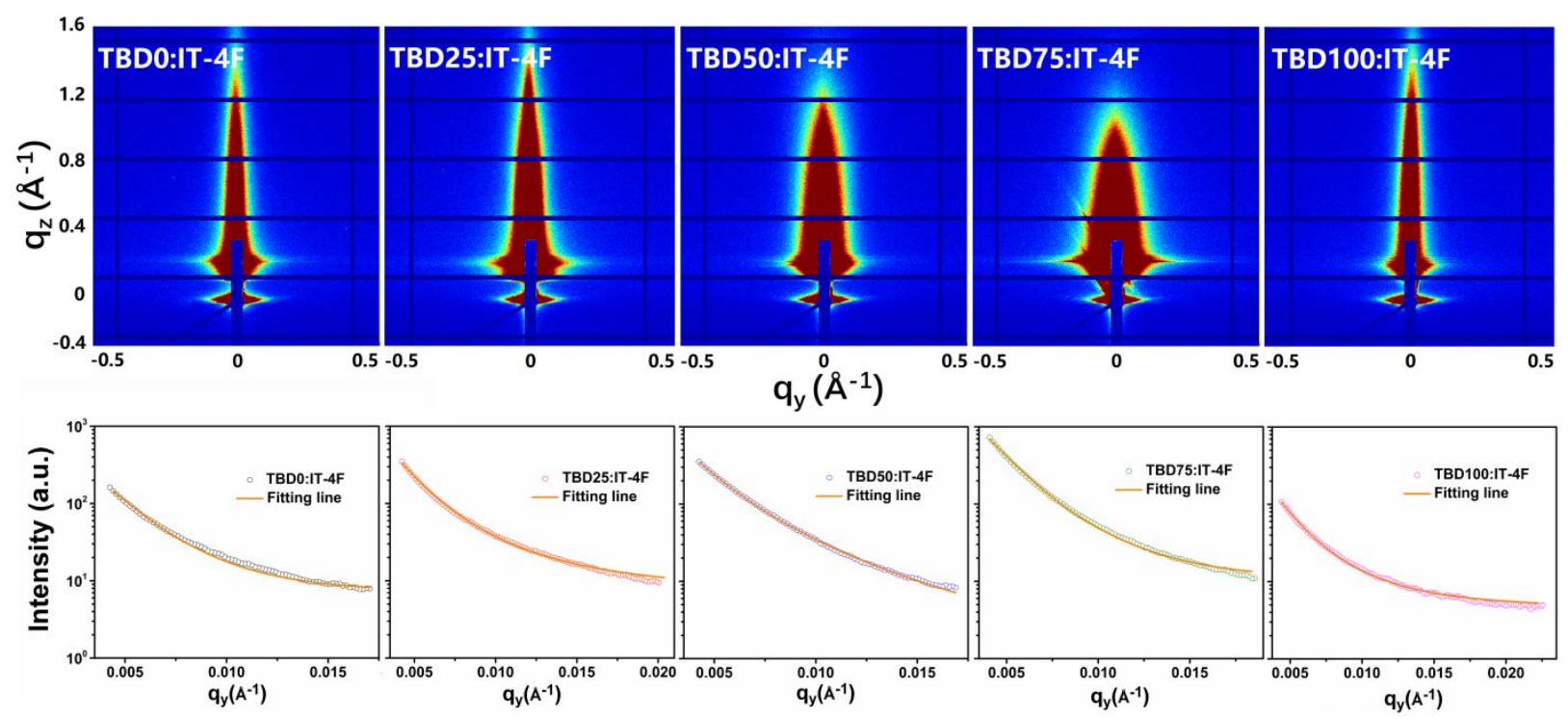

Figure S9 GISAXS patterns of corresponding polymer:IT-4F films and GISAXS profiles along $\mathrm{q}_{\mathrm{y}}$ axis and the fitting lines. 

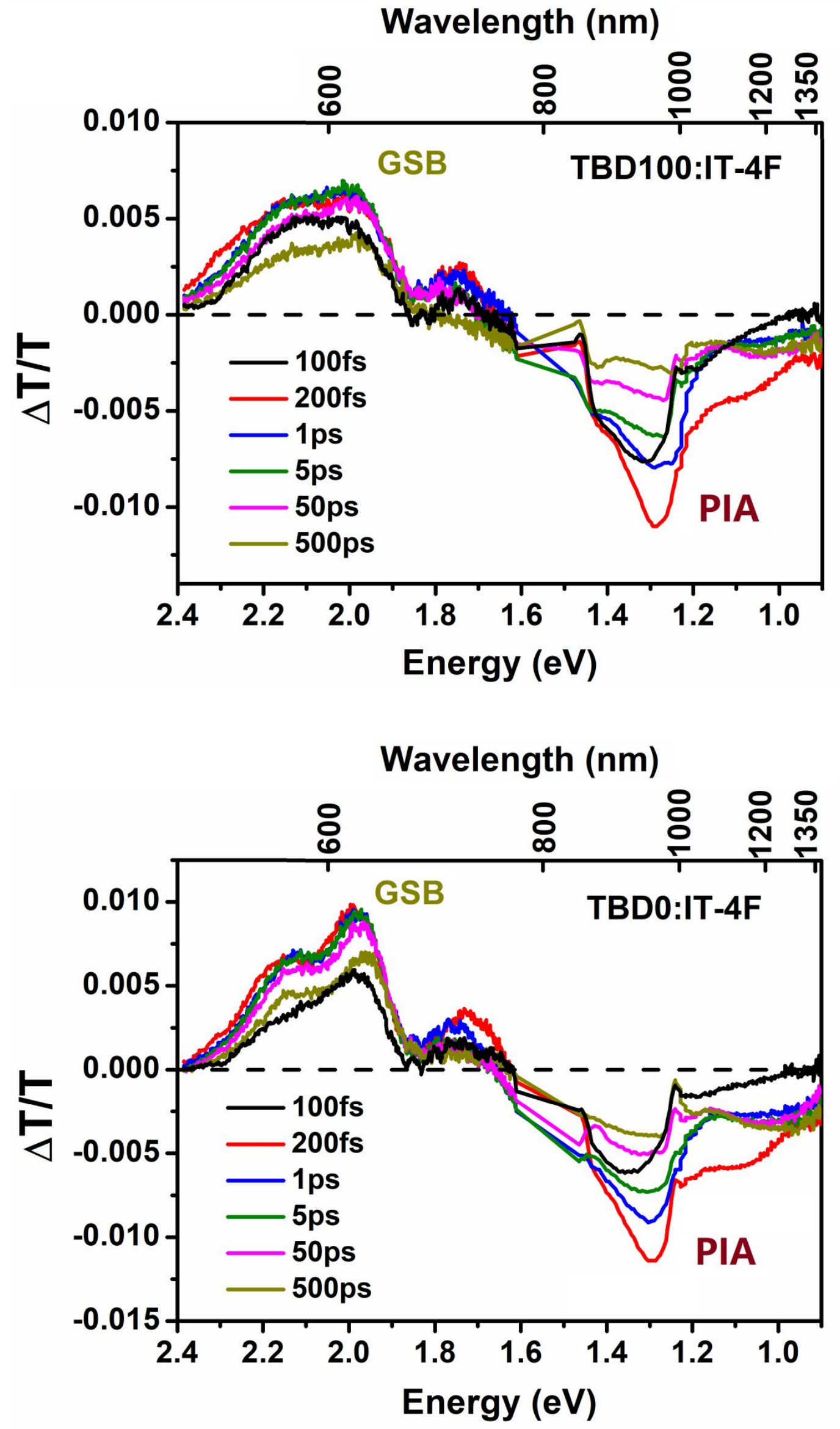

Figure S10. The TA spectra of TBD100:IT-4F and TBD0:IT-4F. 


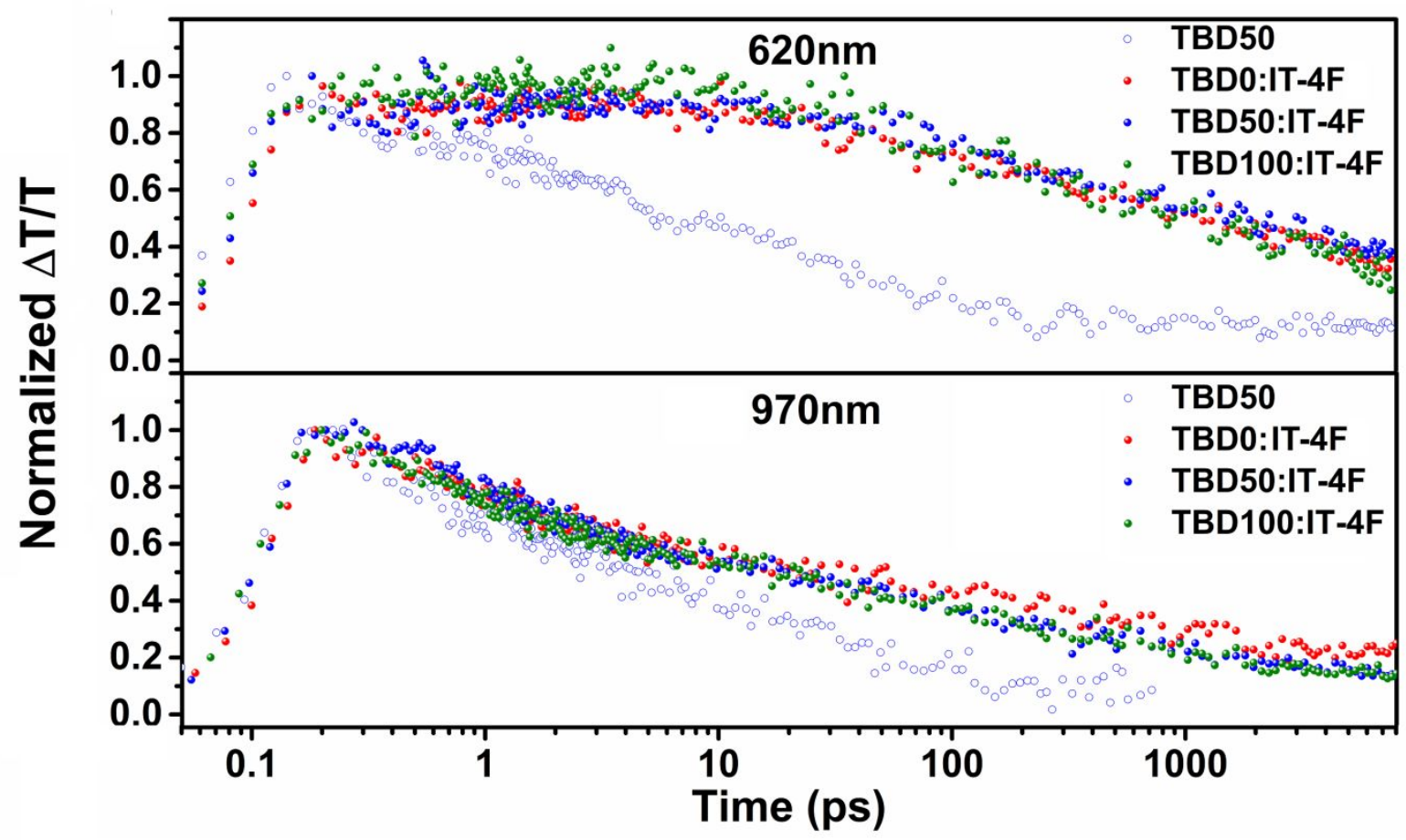

Figure S11. Kinetics for TBD0x:IT-4F(0, 50, 100) blend films at the wavelength of 620 and $970 \mathrm{~nm}$. TA data for the blend following excitation at $500 \mathrm{~nm}$, where the donor absorbs.
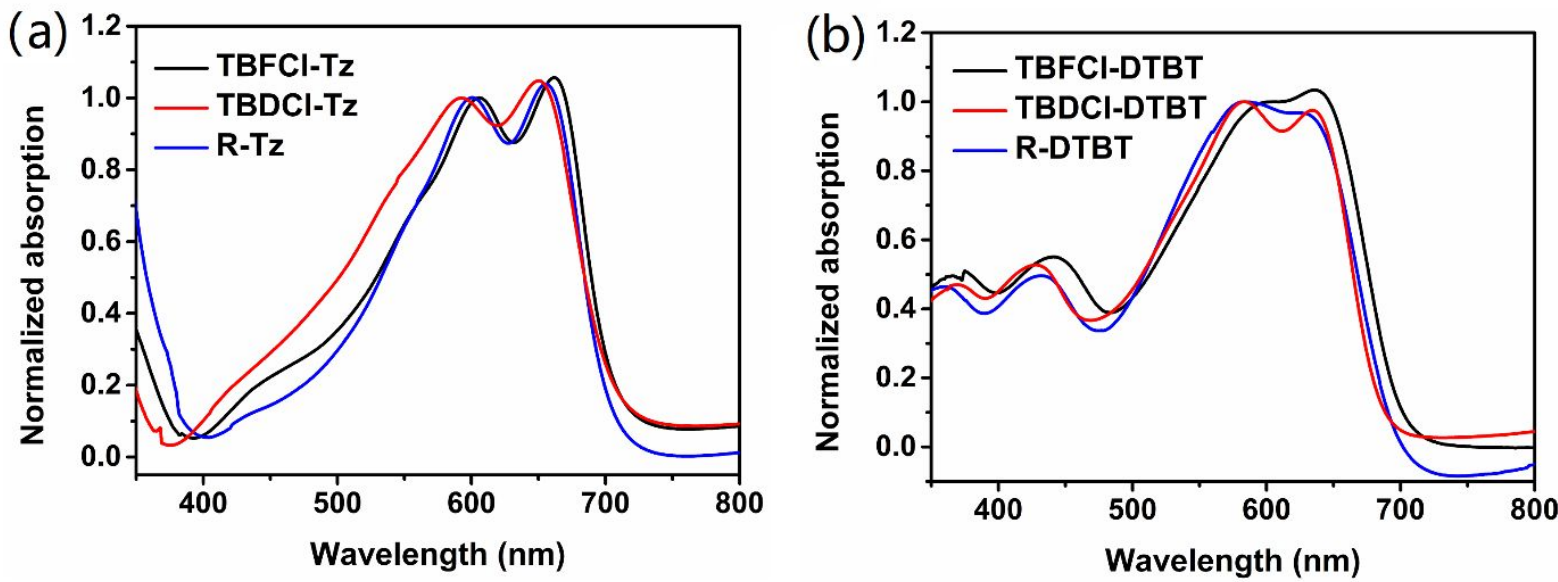

Figure S12. Normalized ultraviolet-visible absorption of (a) Tz-based polymer films and (b) DTBT-based polymer films with the terpolymer strategy. 
Table S4. Photovoltaic performance of the Tz-based devices under different optimized condition

\begin{tabular}{|c|c|c|c|c|c|}
\hline Blend & $\mathrm{D} / \mathrm{A}(\mathrm{w} / \mathrm{w})$ & $V_{\mathrm{OC}}(\mathrm{V})$ & $\left.J_{\mathrm{SC}}(\mathrm{mA} \mathrm{cm})^{-2}\right)$ & $\mathrm{FF}(\%)$ & $\begin{array}{l}\text { Highest } \\
\text { PCE (\%) }\end{array}$ \\
\hline TBFCl-Tz:IT-4F & $1: 1^{\mathrm{a}}$ & $0.892 \pm 0.004$ & $15.4 \pm 0.3$ & $56.7 \pm 1.2$ & 8.1 \\
\hline TBFCl-Tz:IT-4F & $1: 0.8^{\mathrm{a}}$ & $0.885 \pm 0.004$ & $14.8 \pm 0.3$ & $55.1 \pm 1.4$ & 7.5 \\
\hline TBFCl-Tz:IT-4F & $1: 1.25^{\mathrm{a}}$ & $0.891 \pm 0.005$ & $14.3 \pm 0.4$ & $54.4 \pm 1.0$ & 7.2 \\
\hline TBFCl-Tz:IT-4F & $1: 1^{\mathrm{b}}$ & $0.860 \pm 0.005$ & $15.9 \pm 0.4$ & $60.0 \pm 1.5$ & 8.6 \\
\hline TBFCl-Tz:IT-4F & $1: 1^{\mathrm{c}}$ & $0.849 \pm 0.004$ & $17.4 \pm 0.4$ & $62.8 \pm 1.7$ & 9.8 \\
\hline TBDCl-Tz:IT-4F & $1: 1^{\mathrm{a}}$ & $0.883 \pm 0.005$ & $17.0 \pm 0.4$ & $59.0 \pm 1.2$ & 9.2 \\
\hline TBDCl-Tz:IT-4F & $1.0 .8^{\mathrm{a}}$ & $0.886 \pm 0.004$ & $16.9 \pm 0.3$ & $58.8 \pm 1.4$ & 9.1 \\
\hline TBDCl-Tz:IT-4F & $1: 1.25^{\mathrm{a}}$ & $0.878 \pm 0.004$ & $16.5 \pm 0.4$ & $58.9 \pm 1.2$ & 8.8 \\
\hline TBDCl-Tz:IT-4F & $1: 1^{\mathrm{b}}$ & $0.861 \pm 0.005$ & $16.8 \pm 0.3$ & $63.2 \pm 1.7$ & 9.6 \\
\hline TBDCl-Tz:IT-4F & $1: 1^{\mathrm{c}}$ & $0.856 \pm 0.005$ & $18.5 \pm 0.3$ & $63.7 \pm 2.1$ & 10.6 \\
\hline R-Tz:IT-4F & $1: 1^{\mathrm{a}}$ & $0.886 \pm 0.004$ & $17.4 \pm 0.4$ & $65.8 \pm 1.4$ & 10.5 \\
\hline R-Tz:IT-4F & $1.0 .8^{\mathrm{a}}$ & $0.882 \pm 0.006$ & $17.3 \pm 0.3$ & $63.9 \pm 1.7$ & 10.1 \\
\hline R-Tz:IT-4F & $1: 1.25^{\mathrm{a}}$ & $0.886 \pm 0.004$ & $17.7 \pm 0.3$ & $62.8 \pm 1.5$ & 10.2 \\
\hline R-Tz:IT-4F & $1: 1^{\mathrm{b}}$ & $0.870 \pm 0.005$ & $18.5 \pm 0.4$ & $66.9 \pm 1.4$ & 11.1 \\
\hline R-Tz:IT-4F & $1: 1^{\mathrm{c}}$ & $0.864 \pm 0.004$ & $20.4 \pm 0.5$ & $70.5 \pm 1.5$ & 13.0 \\
\hline
\end{tabular}

${ }^{\mathrm{a}}$ The as-cast devices. ${ }^{\mathrm{b}}$ Thermal annealed at $130{ }^{\circ} \mathrm{C}$ for 10 minutes. ${ }^{\mathrm{c}}$ Adding DIO $0.5 \%(\mathrm{v} / \mathrm{v})$ and thermal annealing at $130{ }^{\circ} \mathrm{C}$.

Table S5. Photovoltaic performance of DTBT-based devices under different optimized condition

\begin{tabular}{cccccc}
\hline Blend & D/A (w/w) & $V_{\mathrm{OC}}(\mathrm{V})$ & $J_{\mathrm{SC}}\left(\mathrm{mA} \mathrm{cm}^{-2}\right)$ & $\mathrm{FF}(\%)$ & $\begin{array}{c}\text { Highest } \\
\text { PCE (\%) }\end{array}$ \\
\hline TBFCl-DTBT:IT-4F & $1: 1^{\mathrm{a}}$ & $0.880 \pm 0.004$ & $8.7 \pm 0.3$ & $47.5 \pm 1.3$ & 3.8 \\
TBFCl-DTBT:IT-4F & $1: 0.8^{\mathrm{a}}$ & $0.881 \pm 0.004$ & $8.1 \pm 0.2$ & $46.4 \pm 1.0$ & 3.4
\end{tabular}




\begin{tabular}{cccccc}
\hline TBFCl-DTBT:IT-4F & $1: 1.2^{\mathrm{a}}$ & $0.870 \pm 0.005$ & $7.3 \pm 0.3$ & $48.0 \pm 1.2$ & 3.2 \\
TBFCl-DTBT:IT-4F & $1: 1^{\mathrm{b}}$ & $0.877 \pm 0.003$ & $9.9 \pm 0.3$ & $51.0 \pm 1.3$ & 4.6 \\
TBFCl-DTBT:IT-4F & $1: 1^{\mathrm{c}}$ & $0.872 \pm 0.003$ & $12.3 \pm 0.4$ & $51.4 \pm 1.6$ & 6.2 \\
\hline TBDCl-DTBT:IT-4F & $1: 1^{\mathrm{a}}$ & $0.907 \pm 0.004$ & $12.4 \pm 0.3$ & $53.8 \pm 1.4$ & 6.3 \\
TBDCl-DTBT:IT-4F & $1: 0.8^{\mathrm{a}}$ & $0.900 \pm 0.005$ & $12.3 \pm 0.2$ & $54.1 \pm 1.5$ & 6.2 \\
TBDCl-DTBT:IT-4F & $1: 1.25^{\mathrm{a}}$ & $0.906 \pm 0.004$ & $12.0 \pm 0.4$ & $51.5 \pm 1.4$ & 6.0 \\
TBDCl-DTBT:IT-4F & $1: 1^{\mathrm{b}}$ & $0.902 \pm 0.003$ & $13.1 \pm 0.3$ & $60.6 \pm 1.8$ & 7.5 \\
TBDCl-DTBT:IT-4F & $1: 1^{\mathrm{c}}$ & $0.884 \pm 0.004$ & $16.3 \pm 0.3$ & $61.3 \pm 2.0$ & 9.3 \\
\hline R-DTBT:IT-4F & $1: 1^{\mathrm{a}}$ & $0.903 \pm 0.003$ & $15.7 \pm 0.3$ & $59.8 \pm 1.3$ & 8.9 \\
R-DTBT:IT-4F & $1: 0.8^{\mathrm{a}}$ & $0.902 \pm 0.004$ & $14.4 \pm 0.3$ & $60.6 \pm 1.8$ & 8.2 \\
R-DTBT:IT-4F & $1: 1.25^{\mathrm{a}}$ & $0.905 \pm 0.004$ & $14.3 \pm 0.3$ & $58.0 \pm 1.5$ & 7.8 \\
R-DTBT:IT-4F & $1: 1^{\mathrm{b}}$ & $0.880 \pm 0.005$ & $17.3 \pm 0.4$ & $66.5 \pm 1.2$ & 10.6 \\
R-DTBT:IT-4F & $1: 1^{\mathrm{c}}$ & $0.877 \pm 0.004$ & $18.5 \pm 0.3$ & $69.8 \pm 1.4$ & 11.8 \\
\hline The as-cast & & & & \\
\hline
\end{tabular}

${ }^{a}$ The as-cast devices. ${ }^{b}$ Thermal annealed at $110{ }^{\circ} \mathrm{C}$ for 10 minutes. ${ }^{\mathrm{c}}$ Adding DIO $0.5 \%(\mathrm{v} / \mathrm{v})$ and thermal annealing at $110^{\circ} \mathrm{C}$.

Table S6. Photovoltaic performance of TBD50:Y6 devices under different optimized condition

\begin{tabular}{cccccc}
\hline Blend & D/A (w/w) & $V_{\mathrm{OC}}(\mathrm{V})$ & $J_{\mathrm{SC}}\left(\mathrm{mA} \mathrm{cm}^{-2}\right)$ & FF $(\%)$ & $\begin{array}{c}\text { Highest PCE } \\
(\%)\end{array}$ \\
\hline TBD50:Y6 & $1: 1.2^{\mathrm{a}}$ & $0.900 \pm 0.004$ & $24.8 \pm 0.4$ & $53.0 \pm 1.5$ & 12.4 \\
TBD50:Y6 & $1: 1.2^{\mathrm{b}}$ & $0.887 \pm 0.004$ & $24.5 \pm 0.4$ & $58.6 \pm 1.8$ & 13.2 \\
TBD50:Y6 & $1: 1.2^{\mathrm{c}}$ & $0.898 \pm 0.006$ & $24.5 \pm 0.4$ & $60.1 \pm 1.6$ & 12.5 \\
TBD50:Y6 & $1: 1.2^{\mathrm{d}}$ & $0.859 \pm 0.005$ & $24.6 \pm 0.5$ & $62.7 \pm 1.0$ & 13.5 \\
TBD50:Y6 & $1: 1.2^{\mathrm{e}}$ & $0.876 \pm 0.003$ & $24.7 \pm 0.5$ & $66.8 \pm 1.5$ & 15.0 \\
\hline
\end{tabular}

${ }^{\mathrm{a}}$ The as-cast devices. ${ }^{\mathrm{b}}$ Thermal annealed at $110{ }^{\circ} \mathrm{C}$ for 10 minutes. ${ }^{\mathrm{c}}$ Adding $\mathrm{CN} 0.5 \%(\mathrm{v} / \mathrm{v})$ and thermal annealing at $110{ }^{\circ} \mathrm{C} .{ }^{\mathrm{d}}$ Adding DPE $0.5 \%(\mathrm{v} / \mathrm{v})$ and thermal annealing at $110^{\circ} \mathrm{C}$. ${ }^{\mathrm{e}}$ Adding DIO $0.5 \%(\mathrm{v} / \mathrm{v})$ and thermal annealing at $110{ }^{\circ} \mathrm{C}$. 

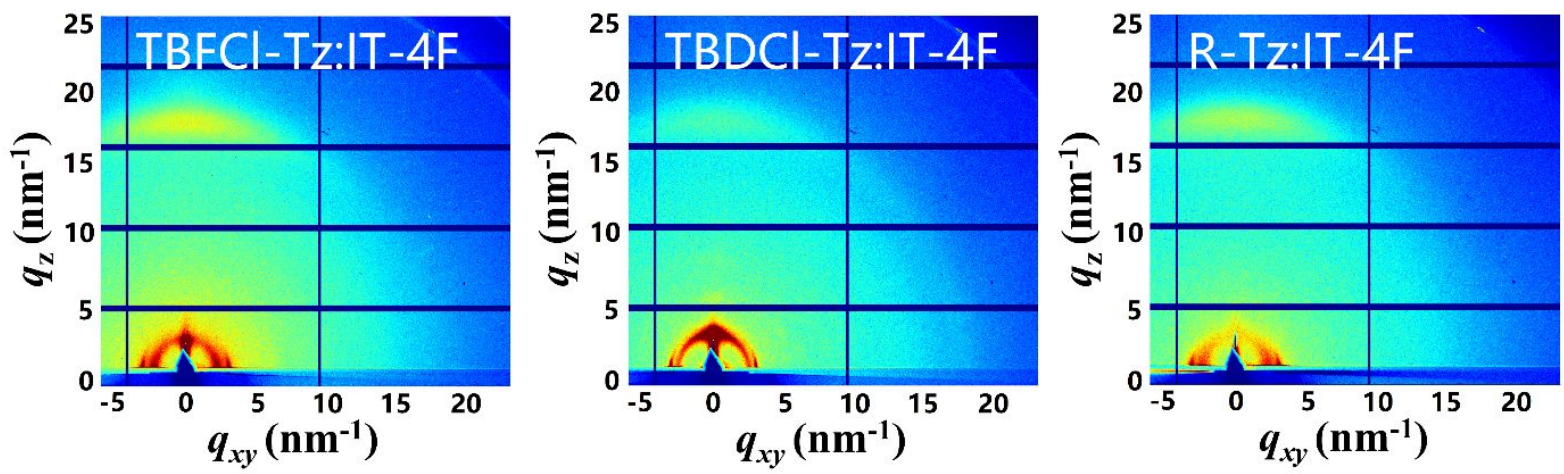

Figure S13. 2D GIWAXS patterns of corresponding polymer:IT-4F blend films.
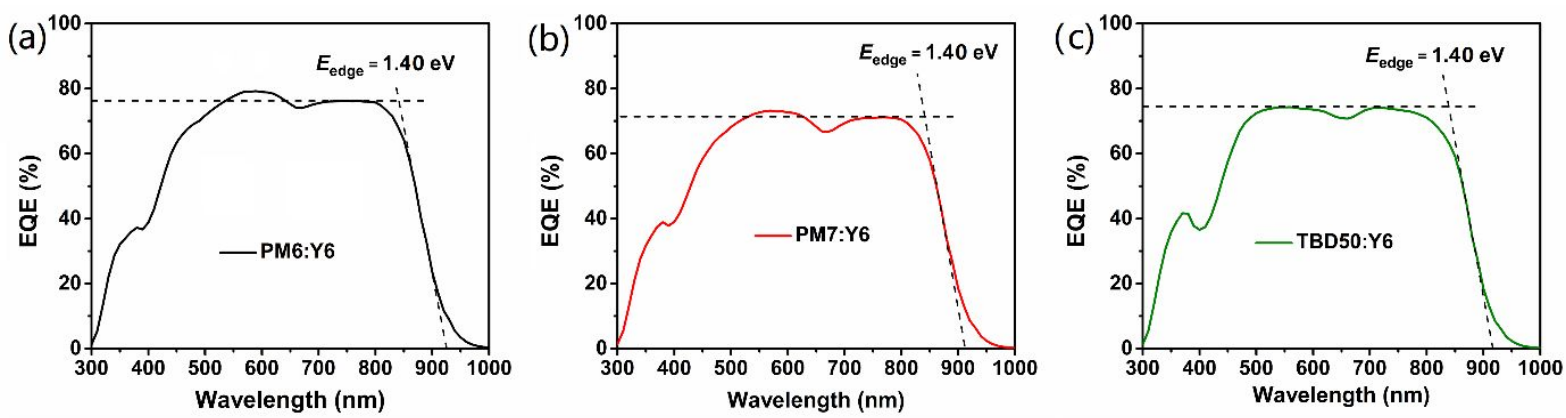

Figure S14. $E_{\text {edge }}$ for (a) PM6:Y6, (b) PM7:Y6 and (c) TBD50:Y6, estimated from EQE spectra.

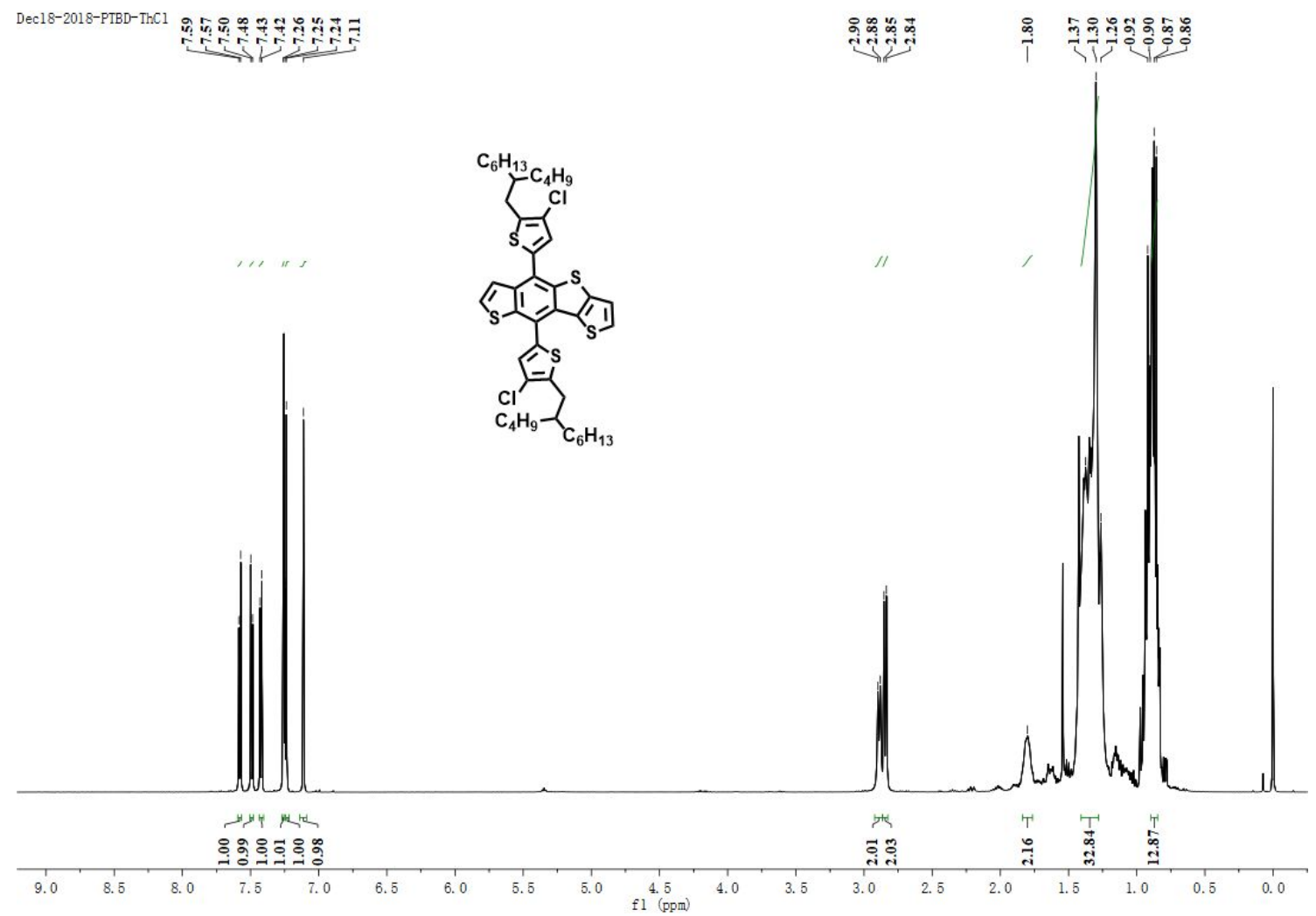

Figure S15. ${ }^{1} \mathrm{H}$ NMR spectrum of compound 2 in $\mathrm{CDCl}_{3}$. 


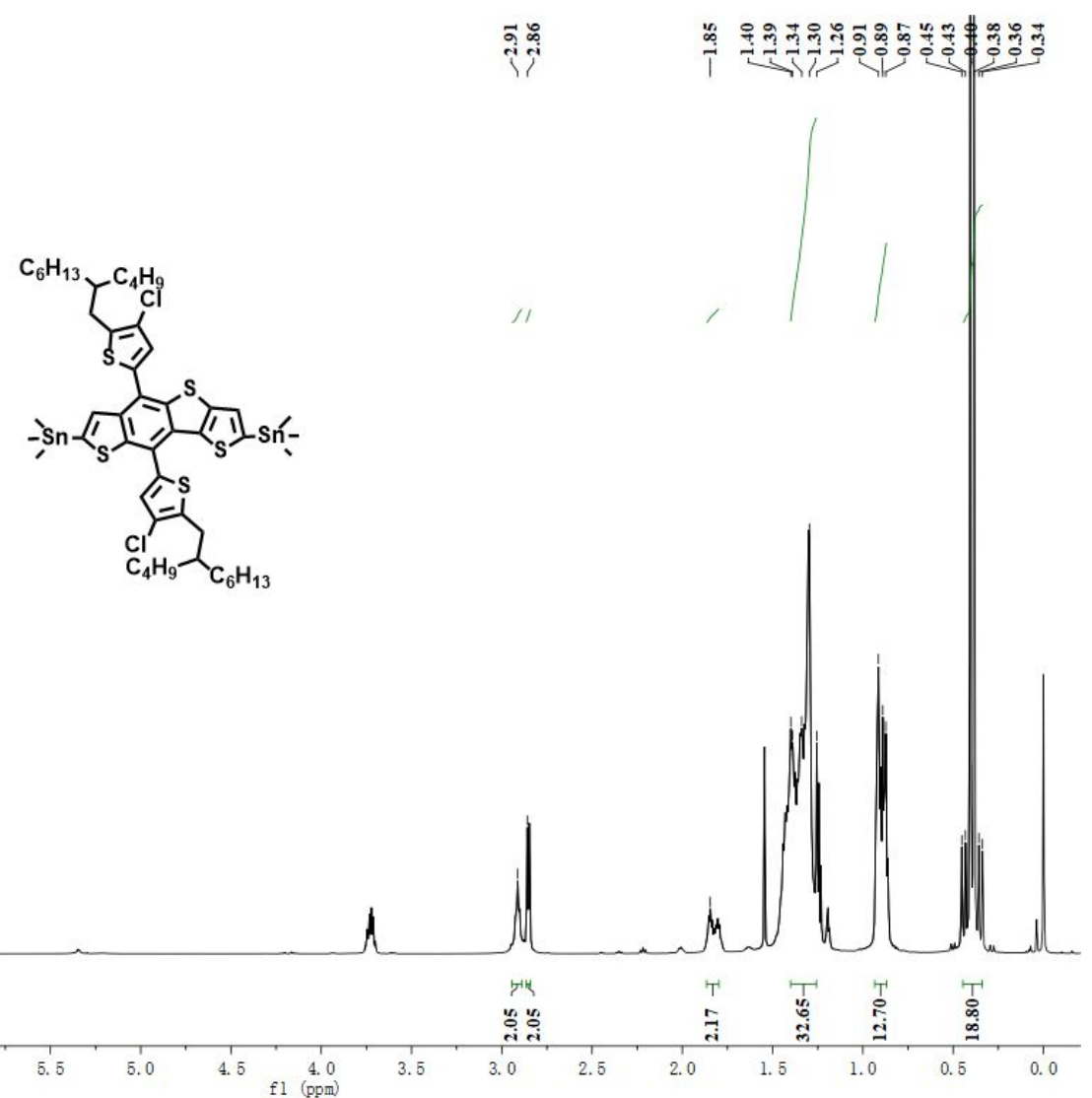

Figure S16. ${ }^{1} \mathrm{H}$ NMR spectrum of $\mathbf{M 1}$ in $\mathrm{CDCl}_{3}$.

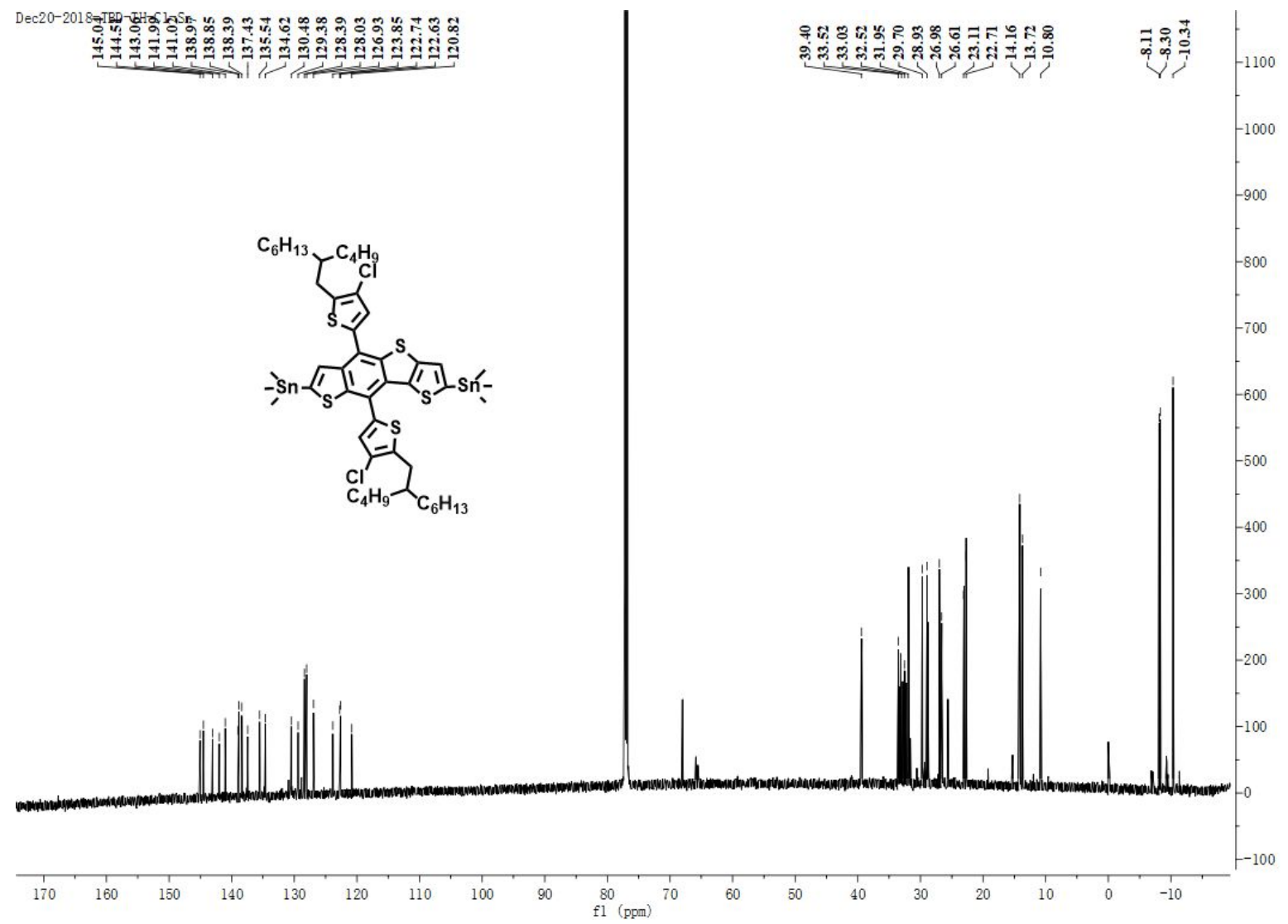

Figure S17. ${ }^{13} \mathrm{C}$ NMR spectrum of $\mathbf{M 1}$ in $\mathrm{CDCl}_{3}$. 


\section{Reference}

[1]. X. Wang, Z. Du, K. Dou, H. Jiang, C. Gao, L. Han, R. Yang, Adv. Energy Mater., 2019, 9, 1802530.

[2]. B. Qiu, R. Cui, J. Yuan, H. Peng, Z. Zhang, Y. Li, Y. Zou, Phys. Chem. Chem. Phys., 2015, 17, 17592-17600.

[3] D. Qian, L. Ye, M. Zhang, Y. Liang, L. Li, Y. Huang, X. Guo, S. Zhang, Z. Tan, J. Hou, Macromolecules, 2012, 45, 9611-9617.

[4] D. Zhu, X. Bao, Q. Zhu, C. Gu, M. Qiu, S. Wen, J. Wang, B. Shahid, R. Yang, Energy Environ. Sci., 2017, 10, 614-620.

[5] J. K. Gallaher, S. K. K. Prasad, M. A. Uddin, T. Kim, J. Y. Kim, H. Y. Woo, J. M. Hodgkiss, Energy Environ. Sci. 2015, 8, 2713-2724.

[6] H. Liao, C. Tsao, T. Lin, C. Chuang, C. Chen, U. Jeng, C. Su, Y. Chen, W. Su, J. Am. Chem. Soc., 2011, 133, 13064-13073

[7] H.-C. Liao, C.-S. Tsao, Y.-T. Shao, S.-Y. Chang, Y.-C. Huang, C.-M. Chuang, T.-H. Lin, C.-Y. Chen, C.-J. Su, U. S. Jeng, Y.-F. Chen, W.-F. Su, Energy Environ. Sci., 2013, 6, 19381948. 